\begin{tabular}{|c|c|}
\hline Title & P53 and meval onate pathway-driven malignancies require A rf 6 for metastasis and drug resistance \\
\hline Author(s) & $\begin{array}{l}\text { Hashimoto, A ri; Oikawa, Tsukasa; Hashimoto, Shigeru; Sugino, Hirokazu; Y oshikawa, A yumu; Otsuka, Yutaro; } \\
\text { Handa, Haruka; Onodera, Y asuhito; Nam, Jin-Min; Oney ama, Chitose; Okada, Masato; Fukuda, Mitsunori; Sabe, } \\
\text { Hisataka }\end{array}$ \\
\hline Citation & $\begin{array}{l}\text { Journal of cell biology, 213(1), 81-95 } \\
\text { https://doi.org/10.1083/jcb.201510002 }\end{array}$ \\
\hline Issue Date & $2016-04-11$ \\
\hline Doc URL & http:/hdl. handle.net/2115/62128 \\
\hline Rights & ๑) Hashimoto et al., 2016. Originally published in Journal of Cell Biology. doi:10.1083ฎcb.201510002 \\
\hline Rights(URL) & http://kreativecommons.org/icenses/by-nc-sa/3.0/ \\
\hline Type & article \\
\hline Additional Information & There are other files related to this item in HUSCAP. Check the above URL. \\
\hline File Information & JCB-2016-Hashimoto-81-95.pdf \\
\hline
\end{tabular}

Instructions for use 


\title{
P53- and mevalonate pathway-driven malignancies require Arf6 for metastasis and drug resistance
}

\author{
Ari Hashimoto,' Tsukasa Oikawa, ${ }^{1}$ Shigeru Hashimoto, ${ }^{1}$ Hirokazu Sugino, 1 Ayumu Yoshikawa, ${ }^{1}$ Yutaro Otsuka, ${ }^{1}$ \\ Haruka Handa, ${ }^{1}$ Yasuhito Onodera, ${ }^{1}$ Jin-Min Nam, ${ }^{2}$ Chitose Oneyama, ${ }^{3}$ Masato Okada, ${ }^{3}$ Mitsunori Fukuda, ${ }^{4}$ and \\ Hisataka Sabe ${ }^{1}$ \\ 'Department of Molecular Biology, Graduate School of Medicine and 2 Global Institution for Collaborative Research and Education, Hokkaido University, Sapporo \\ 060-8638, Japan \\ ${ }^{3}$ Institute for Microbial Diseases, Osaka University, Osaka 565-0871, Japan \\ ${ }^{4}$ Department of Developmental Biology and Neurosciences, Graduate School of Life Sciences, Tohoku University, Sendai 980-8578, Japan
}

Drug resistance, metastasis, and a mesenchymal transcriptional program are central features of aggressive breast tumors. The GTPase Arf6, often overexpressed in tumors, is critical to promote epithelial-mesenchymal transition and invasiveness. The metabolic mevalonate pathway (MVP) is associated with tumor invasiveness and known to prenylate proteins, but which prenylated proteins are critical for MVP-driven cancers is unknown. We show here that MVP requires the Arf6-dependent mesenchymal program. The MVP enzyme geranylgeranyl transferase II (GGT-II) and its substrate Rabl 1b are critical for Arf6 trafficking to the plasma membrane, where it is activated by receptor tyrosine kinases. Consistently, mutant p53, which is known to support tumorigenesis via MVP, promotes Arf6 activation via GGT-II and Rab1 1b. Inhibition of MVP and GGT-II blocked invasion and metastasis and reduced cancer cell resistance against chemotherapy agents, but only in cells overexpressing Arf6 and components of the mesenchymal program. Overexpression of Arf6 and mesenchymal proteins as well as enhanced MVP activity correlated with poor patient survival. These results provide insights into the molecular basis of MVP-driven malignancy.

\section{Introduction}

The mevalonate pathway (MVP) has long been recognized as an excellent target of cancer therapeutics, partly as a result of its activity to prenylate and hence activate small GTPases, including members of the Ras and Rho family, which are key players in oncogenesis and cancer malignancy (Goldstein and Brown, 1990). MVP is involved in a wide variety of aspects of cell regulation under both normal and disease conditions (Yeganeh et al., 2014). Statins are inhibitors of hydroxymethylglutaryl-CoA reductase (HMGCR), a rate-limiting enzyme of MVP, and were originally developed to lower cholesterol levels, such as in cardiovascular disease (Endo et al., 1976). However, in spite of such potentials of statins, which inhibit the activities of Ras and Rho family members, many clinical trials showed that statins on their own or even in combination with other drugs or with radiation therapy did not always effectively treat cancers (Jukema et al., 2012; Yeganeh et al., 2014; Altwairgi, 2015). Therefore, the general functions of MVP, which may play roles in most cancer cells, might not be crucial for promoting cancer malignancy. However, MVP inhibitors might still become very effective

Correspondence to Hisataka Sabe: sabeh@med.hokudai.ac.jp

Abbreviations used in this paper: ccRCC, clear cell renal cancer cell; EGFR EGF receptor; GGT, geranylgeranyl transferase; HGF, hepatocyte growth factor; HMGCR, hydroxymethylglutaryl-CoA reductase; Irr, irrelevant sequence; MVA, mevalonic acid; MVP, mevalonate pathway; $\mathrm{PH}$, pleckstrin homology; $\mathrm{PM}$ plasma membrane; RTK, receptor tyrosine kinase; SIM, structured illumination microscopy; wt, wild type.

The Rockefeller University Press $\$ 30.00$

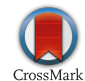

therapeutics for cancer if they are combined with biomarkers to identify the "responders" (see the last paragraph of Introduction and the last paragraph of Discussion).

An example of the critical roles played by MVP in breast cancer was recently shown in detail. Gain-of-function mutants of p53 may interact with the sterol regulatory element-binding proteins SREBP-1 and SREBP-2 to up-regulate the transcription of genes involved in fatty acid and sterol biosynthetic pathways, including MVP (Freed-Pastor et al., 2012). Through the upregulation of MVP activity, mutant p53 enhances the invasiveness of breast cancer cells, such as MDA-MB-231 (Freed-Pastor et al., 2012), which expresses R280K mutant p53 and has lost the other TP53 allele (Wasielewski et al., 2006). However, although MDA-MB-468 cells also express mutant p53 (R273H), which up-regulates MVP, the up-regulation of MVP by mutant p53 in this cell line did not promote invasiveness but only disrupted the cell morphology (Freed-Pastor et al., 2012). These results clearly demonstrate that MVP, as well as its enhanced activity, can be linked to cancer invasiveness, although this link seems to depend on cell contexts, even within the same type of cancer. However, the detailed molecular mechanisms by which

(C) 2016 Hashimoto et al. This article is distributed under the terms of an AttributionNoncommercial-Share Alike-No Mirror Sites license for the first six months after the publication date (see http://www.rupress.org/terms). After six months it is available under a Creative Commons License (Attribution-Noncommercial-Share Alike 3.0 Unported license, as described at http://creativecommons.org/licenses/by-nc-sa/3.0/). 
certain breast cancer cells respond to the enhanced activity of MVP to promote invasiveness remain unidentified.

The small GTPase Arf6 and its signaling proteins are frequently overexpressed in different types of cancers, such as breast cancer, clear cell renal cell carcinoma, lung adenocarcinoma, and head and neck squamous cell carcinoma, and constitute a pathway promoting invasion and metastasis by down-regulating E-cadherin-based cell-cell adhesion and up-regulating recycling of $\beta 1$ integrins (Hashimoto et al., 2004a, 2006, 2016; Onodera et al., 2005; Morishige et al., 2008; Menju et al., 2011; Kinoshita et al., 2013; Sato et al., 2014). In this pathway, Arf6 is activated by receptor tyrosine kinases (RTKs), such as EGF receptor (EGFR) via GEP100 (also called BRAG2) in breast cancer cells (Morishige et al., 2008), whereas Arf6 is activated by lysophosphatidic acid receptors via EFA6 in clear cell renal cancer cells (ccRCCs; Hashimoto et al., 2016). Activated Arf6 then recruits AMAP1 (Onodera et al., 2005). We have recently identified that EPB41L5, which is expressed exclusively in mesenchymal cells under normal conditions and acts to promote cell motility and focal adhesion dynamics (Hirano et al., 2008), is an integral binding partner of AMAP1 for invasion and metastasis (unpublished data). Thus, this Arf6-based pathway is a cancer-specific mesenchymal-type signaling pathway. It should be noted that Arf6 is acylated but is not prenylated and hence is not a direct target of the MVP activity.

Possibly related to the results by Freed-Pastor et al. (2012), it should be noted that MDA-MB-231 cells overexpress Arf6 and its signaling components, including the mesenchymalspecific EPB41L5, and use them for invasion and metastasis, whereas MDA-MB-468 cells express these molecules at marginal levels (Hashimoto et al., 2004a; Onodera et al., 2005). Moreover, several studies have shown that the acquisition of mesenchymal properties by cancer cells, particularly breast cancer cells, is significantly associated with their resistance to therapeutic drugs (Tryndyak et al., 2010; Yu et al., 2013; Fischer et al., 2015; Zheng et al., 2015), although the underlying molecular mechanisms remain unidentified. Here, we investigated whether MVP activity is involved in activation of the Arf6based mesenchymal pathway, with the aim to identify a key link between MVP and cancer malignancy. For this purpose, we primarily used breast cancer cells, in which the roles of MVP and the overexpressed Arf6 pathway, as well as the acquisition of mesenchymal properties in the development of malignancy (particularly drug resistance), have been well documented. Our results revealed the molecular basis as to why MVP inhibitors are highly effective against only a certain population of cancer cells and proposed biomarkers that might be useful for identifying cancer cells that are highly sensitive to the inhibition of MVP activity, such as by statins.

\section{Results}

TGF $\beta 1$ activates Arf6 via trans-activating c-Met to promote invasiveness

Both the activity of MVP up-regulated by mutant p53 and the Arf6-based pathway activated by RTKs were reported to be crucial for the enhanced invasiveness of MDA-MB-231 cells, as mentioned in the second and third paragraphs of the Introduction. Moreover, TGF $\beta 1$ signaling was also pivotal for the enhanced invasiveness of this cell line (Adorno et al., 2009). To understand the precise roles of MVP in this enhanced invasiveness, we first investigated the association of these events and found that TGF $\beta 1$ activates Arf6 in MDA-MB-231 cells (Fig. 1 A), as assessed by the GGA pull-down assay. siRNA-mediated Arf6 silencing abolished the TGF $\beta 1$-induced invasion (Fig. $1 \mathrm{~B}$ and Fig. S1 A). Silencing of GEP100 also blocked Arf6 activation and cell invasion, and silencing of $A M A P 1$ blocked the invasion (Fig. 1, B and C; and Fig. S1 A). Cell viability was not notably affected under these conditions (Fig. S1 B). Therefore, TGF $\beta 1$ signaling appears to use the Arf6 pathway to promote the invasiveness of MDA-MB-231 cells.

The TGF $\beta 1$ receptor is not a member of the RTKs, although TGF $\beta$ may trans-activate some RTKs (Uchiyama-Tanaka et al., 2002). c-Met (hepatocyte growth factor [HGF] receptor) was clearly tyrosine phosphorylated by TGF $\beta 1$ in MDA-MB-231 cells (Fig. $1 \mathrm{D}$ ), and silencing of $c$-Met blocked TGF $\beta 1$-induced Arf6 activation and cell invasion (Fig. 1, E and F; and Fig. S1, C and J). HGF on its own was able to activate Arf6 and cell invasion, whereas these activations were abolished by the silencing of GEP100 (Fig. 1, B and C). AMAP1 silencing also blocked HGF-induced cell invasion (Fig. 1 B). However, TGF $\beta 1$ only marginally activated EGFR in these cells (Fig. S1 D). Consistently, the c-Met inhibitor PHA665752 blocked TGF $\beta 1$-induced Arf6 activation and cell invasion almost completely, without affecting Smad2 phosphorylation or cell viability (Fig. S1, E-H). c-Met uses Gab1 in its intracellular signaling. Silencing of $\mathrm{Gabl}$ blocked TGF $\beta 1$-induced Arf6 activation and cell invasion without affecting cell viability (Fig. 1, E and F; and Fig. S1, I and J). We also confirmed that c-Met and GEP100 are coprecipitated with Gab1 upon HGF stimulation (Fig. S1 K) and that the pleckstrin homology (PH) domain of GEP100, fused to GST, precipitated Gab1 and c-Met upon TGF $\beta 1$ stimulation (Fig. S1 L). Therefore, it is likely that via the trans-activation of c-Met, TGF $\beta 1$ activates Arf6 in MDA-MB-231 cells.

Mutant p53 is critical for the activation of Arfo but not c-Met

We then analyzed the association between mutant p53 and ligand-induced Arf6 activation. Silencing of mutant p53 in MDA-MB-231 cells (resulting in shp53 cells) was shown to block TGF $\beta 1$-induced invasion (Adorno et al., 2009). We previously generated shp53 cells expressing normal p53 (shp53/wild-type [wt] cells), as well as shp53 cells expressing the oncogenic p53 mutants R175H, R249S, and R273H and the rescue construct of R280K (shp53/R175H cells, shp53/R249S cells, shp53/R273H cells, and shp53/R280K cells, respectively; unpublished data). These exogenous p53 proteins were tagged with V5. We here found that TGF $\beta 1$-induced Arf6 activation and cell invasion are substantially abolished in shp53 cells and shp53/wt cells, but not in cells expressing mutant p53 proteins (Fig. 2, A and B). Similar results were also observed upon EGF and HGF stimulation (Fig. 2, A and B). However, TGF $\beta 1$-induced phosphorylation of c-Met (Fig. 2 C) and the ligand-induced activation of RTKs and Akt occurred even in shp53 cells and shp53/wt cells (Fig. S2 A). This association of GEP100 with EGFR also occurred in these cells upon EGF stimulation (Fig. S2 B). Therefore, different mutant $\mathrm{p} 53$ proteins are involved in ligand-induced Arf6 activation. However, these results showed that mutant p53 proteins are dispensable to the trans-activation of c-Met by TGF $\beta 1$. Moreover, the ability of R280K to promote Arf6 activation and cell invasion appeared to be primarily dependent on its transcriptional activity, as its transcription-dead mutant (txn-dead R280K) was unable to restore these activities (Fig. S2, C and D). 
A

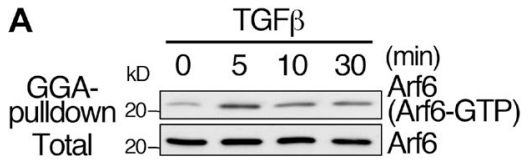

C
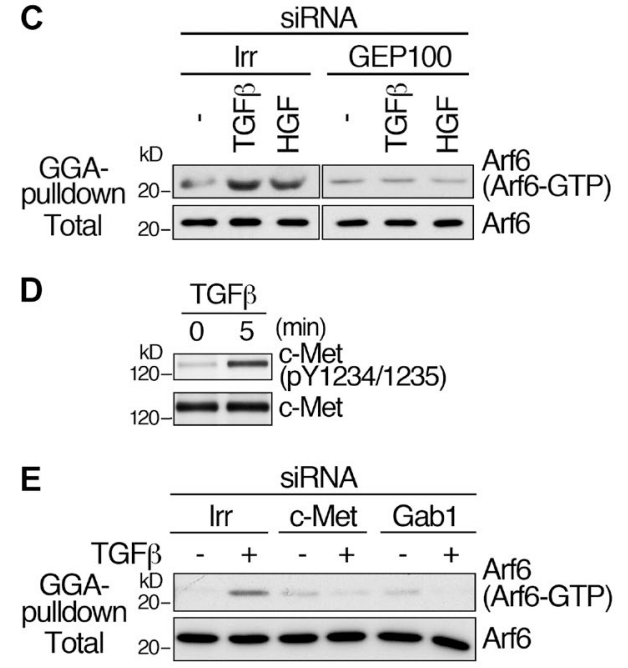

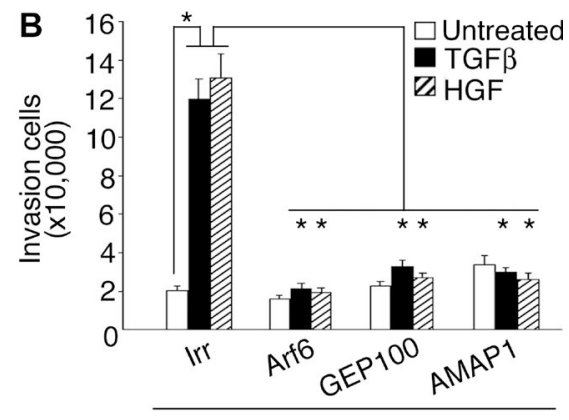

SiRNA

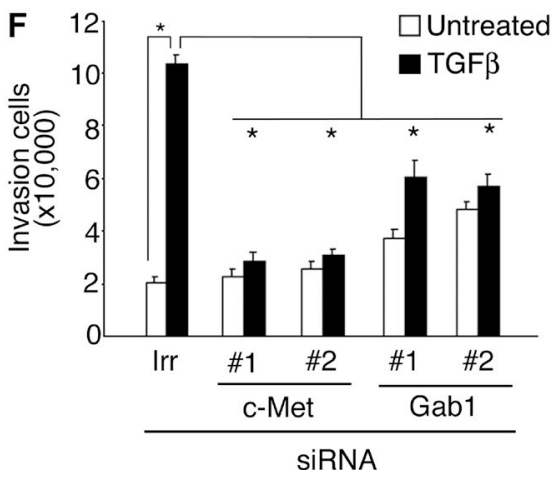

Figure 1. TGF $\beta 1$ activates Arf6 to promote the invasion of MDA-MB-231 cells. (A) Arf6 activities upon the stimulation of serum-starved cells by TGF $\beta 1$ for the indicated times were measured by detecting Arf6-GTP and total Arf6 by anti-Arf6 immunoblotting. (B) Matrigel invasion activities were measured in cells pretreated with the indicated siRNAs or siRNA with an irrelevant sequence (Irr) in the presence or absence of TGF $\beta 1$ or HGF. The number of cells that invaded through the Matrigel to the lower surface of the filters was scored as described in the Matrigel invasion assay section within Materials and methods. (C) TGF $\beta 1$ - and HGF-induced Arf6 activation were measured in cells pretreated with siRNAs for GEP100 or Irr. (D) Activation of c-Met upon TGF 1 stimulation was detected by a c-Met pY1234/1235 antibody together with total c-Met by immunoblotting. ( $E$ and F) TGF $\beta$ 1induced Arf6 activities (E) and Matrigel invasion activities (F) were measured in cells pretreated with the indicated siRNAs or Irr. Matrigel invasion activities were measured as in $B$. The results represent mean \pm SEM. $n=3 .{ }^{*}, P<0.001$. Total, total cell lysate. sively dependent on Arf6 for invasion (Hashimoto et al., 2004a. Onodera et al., 2005). These results indicate that different mutant p53 proteins are involved in ligand-induced Arf6 activation in different breast cancer cells to enhance invasiveness.

MVP is necessary for Arfo activation

We next investigated the association between MVP and ligand-induced Arf6 activation. Simvastatin, Mevastatin, or 6-fluoromevalonate, an inhibitor of mevalonate pyrophosphate decarboxylase, all blocked the invasive phenotypes of MDA-MB-231 cells (Freed-Pastor et al., 2012). We found that these inhibitors block TGF $\beta 1$-induced Arf6 activation and invasion (Fig. 3, A and B) without affecting c-Met trans-activation (Fig. $3 \mathrm{C}$ ) or cell viability (Fig. S2 E). The readdition of mevalonic acid (MVA) and MVA-phosphate restores Arf6 activation and invasion (Fig. 3, A and B). HGF-induced Arf6 activation of MDA-MB-435s cells and Hs578T cells was also blocked by Simvastain (Fig. 3 D). Therefore, MVP appears to be crucial for ligand-induced Arf6 activation in different breast cancer cells.

Mutant p53 and geranylgeranyl transferase II (GGT-II] are crucial for the plasma membrane (PM) recruitment of Arf6 We then sought to understand the precise mechanisms by which MVP as well as mutant p53 is involved in Arf6 activation. GDP-Arf6 is predominantly localized at the cytoplasm and is recruited to the PM during its activation by RTKs (Hashimoto et al., 2004b). We noticed that the PM recruitment of Arf6 upon TGF $\beta 1$ treatment is substantially impaired in shp53 cells and shp53/wt cells, as compared with their parental cells (Fig. 3, E and F). However, inhibition of MVP is known to substantially alter cell morphology (Freed-Pastor et al., 2012); hence, we were unable to determine whether MVP is crucial for the PM recruitment of Arf6 using statins.

To verify the involvement of MVP, we then identified the enzymes involved. GGT and farnesyl transferase act under MVP. Inhibition of GGT by GGTI-2133 blocked the invasive phenotypes of MDA-MB-231 cells, whereas the inhibition of farnesyl transferase by FTI-277 did so only slightly (Freed-Pastor et al., 2012). Consistently, GGTI-2133, but not FTI-277, effectively blocked the ligand-induced Arf6 activation of MDA-MB-231, MDA-MB-435s, and Hs578T cells (Fig. 3 G). GGT consists of two isoforms, GGT-I and GGT-II. Silencing of GGT-II blocked Arf6 activation and cell invasion, whereas silencing of GGT-I only blocked the invasion (Fig. 3, H and I). Cell viability was not affected by these siRNA treatments (Fig. S2, F and G). Moreover, silencing of GGT-II, but not GGT-I, blocked the PM recruitment of Arf6 induced by TGF $\beta 1$ (Fig. 3, J and K; and Fig. S2, H and I). Therefore, GGT-II appears to be crucial for the PM recruitment of Arf6 and hence for Arf6 activation by external ligands. 
A MDA-MB-231

$\operatorname{shp53}$
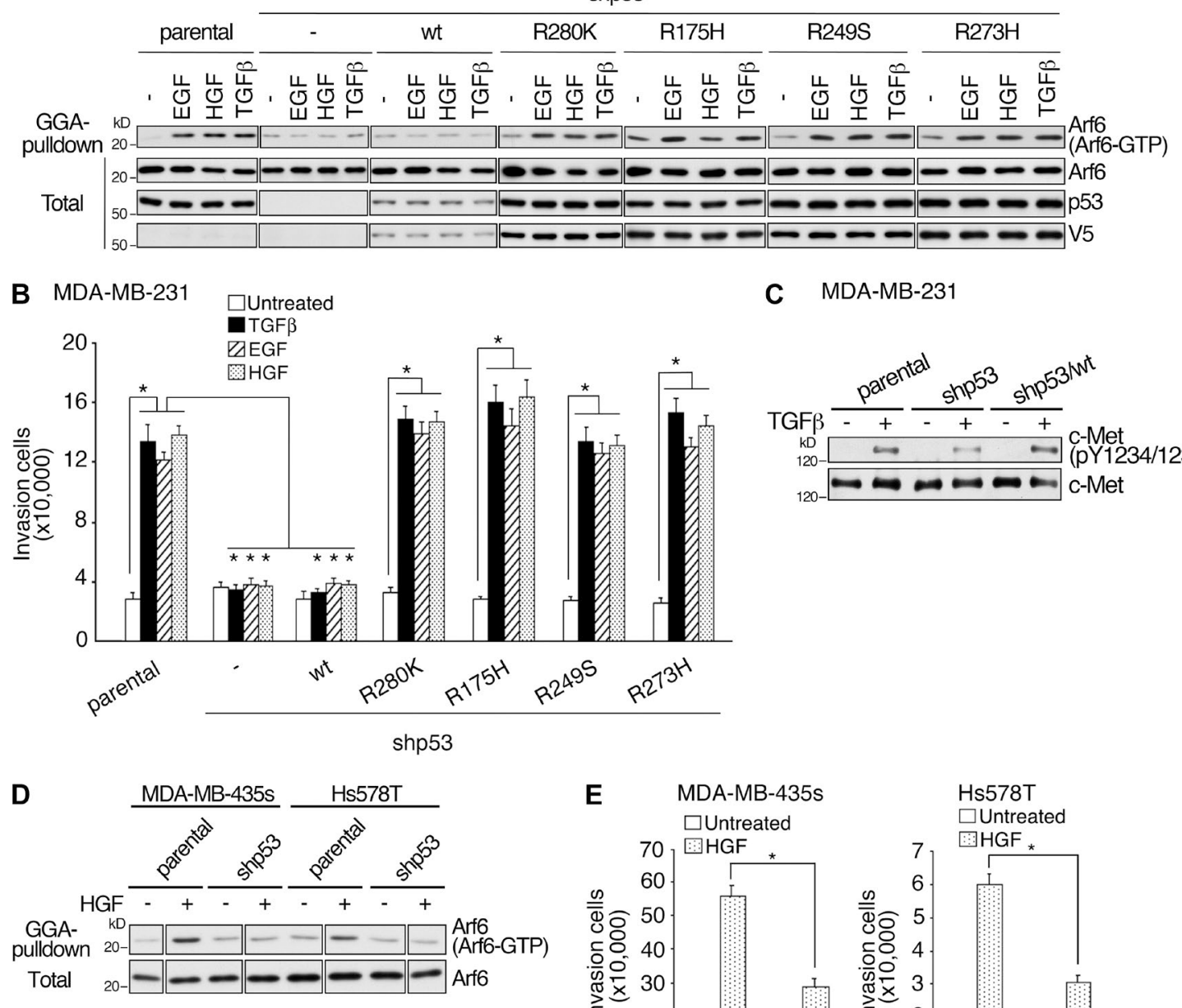

C MDA-MB-231

Figure 2. Mutant p53 is crucial for ligand-induced Arf6 activation but not for the trans-activation of c-Met. (A and B) Arf6 activation (A) and Matrigel invasion (B), induced by EGF, HGF, or TGF $\beta 1$, as indicated, were measured in MDA-MB-231 cells (parental) and their p53 derivatives. Exogenous p53 proteins were tagged with V5. Matrigel invading cells were quantified as described in the Matrigel invasion assay section within Materials and methods. (C) TGF $\beta 1$ induces c-Met activation irrespective of p53 status. Activation of c-Met upon 5 min TGF $\beta 1$ stimulation of MDA-MB-231 cells and their p53 derivatives was detected using the pY1234/1235 antibody. (D and E) HGF-induced Arf6 activation (D) and Matrigel invasion activities (E) of MDA-MB-435s cells, Hs578T cells, and their shp53 cells were measured. Matrigel invasion activities were measured as in $B$. The results represent mean \pm SEM. $n=3$. $*, P<0.001$. Total, total cell lysate.

Rab11 with Arf6 to play essential roles in the PM recruitment of Arf6

Arf6 on its own cannot determine the destination of its own intracellular trafficking. Likewise, the functional cooperation of Arf6 with other small GTPases has been well documented (Grant and Donaldson, 2009). We identified molecules acting downstream of GGT-II to recruit Arf6 to the PM. GGT-II is involved in the lipid modification of the Rab family small GTPases, whereas GGT-I is involved in the lipid modification of Rap-GTPases (Wiemer et al., 2011). Screening of a Rab-GTPase siRNA library revealed the possible involvement of Rab3b, Rab5c, Rab7b, Rab11a, and Rab11b in the invasion of MDA-MB-231 cells (Fig. S3 A). Rab5c was previously shown to be essential for invasion but not for Arf6 recruitment (Onodera et al., 2012). After confirming positive roles of those Rab proteins in invasion (Fig. 4 A and Fig. S3, B and C), we found that Rab11a and Rab11b, but not Rab3b or Rab7b, are required for Arf6 activation upon stimulation by TGF $\beta 1$, HGF, and EGF in MDA-MB-231 cells (Fig. 4 B). Moreover, silencing of both Rab11a and Rab11b blocked Arf6 activation almost completely (Fig. 4 B and Fig. S3 C). Therefore, it is likely that Rab11a and Rab11b are able to independently contribute to Arf6 activation. However, although Rab11c (also called Rab25) is a Rab11 family member, it was not expressed at detectable levels in the breast cancer cell lines that we examined, including MDA-MB-231 (Fig. S4 A).

Like Arf6, the functions of Rab11 are associated with the recycling of endosomes (Stenmark, 2009). Using fluorescence protein tags, we then found that Rab11b is colocalized with Arf6 to a certain extent in the cytoplasm and that Rab11a is also colocalized with Arf6, but to a lesser extent than Rab11b (Fig. 4, C and D). We confirmed the colocalization of endogenous Rab11b with Arf6-EGFP using an antibody applicable to the detection of Rab11b in fixed cells (Fig. 4 E). Silencing of Rab11a and Rab11b each blocked the PM recruitment of Arf6 upon TGF $\beta 1$ stimulation to a certain extent (Fig. 4, F and G). 
A MDA-MB-231

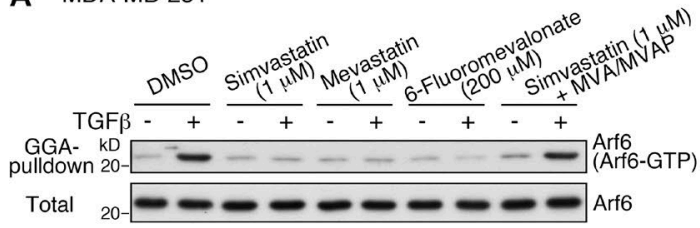

B MDA-MB-231 $\quad$ aUntreated

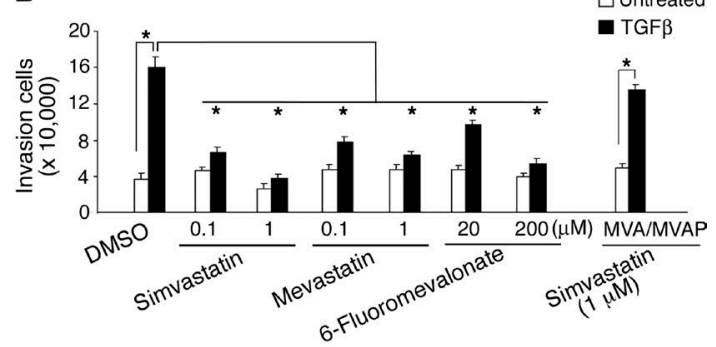

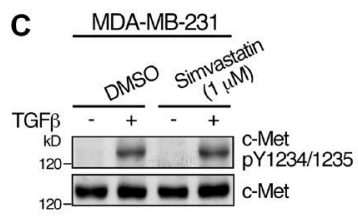

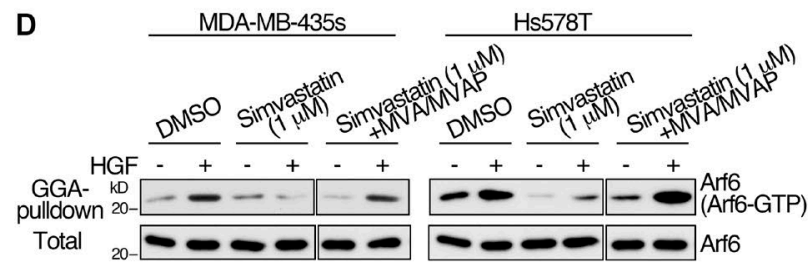

E

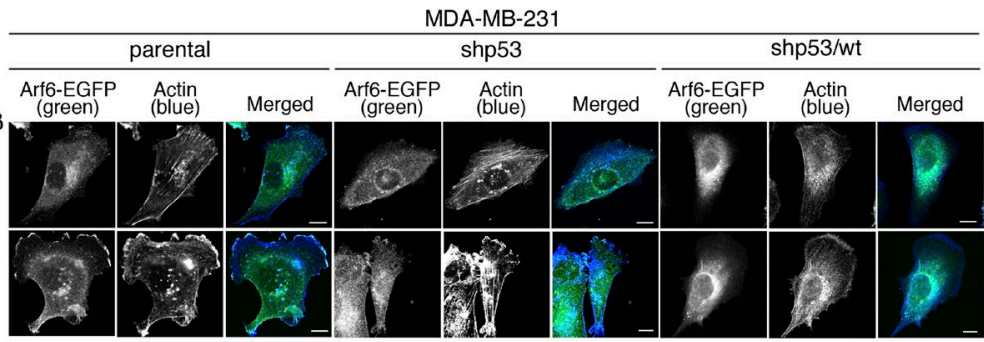

F MDA-MB-231

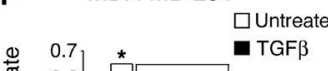

TGF $\beta$
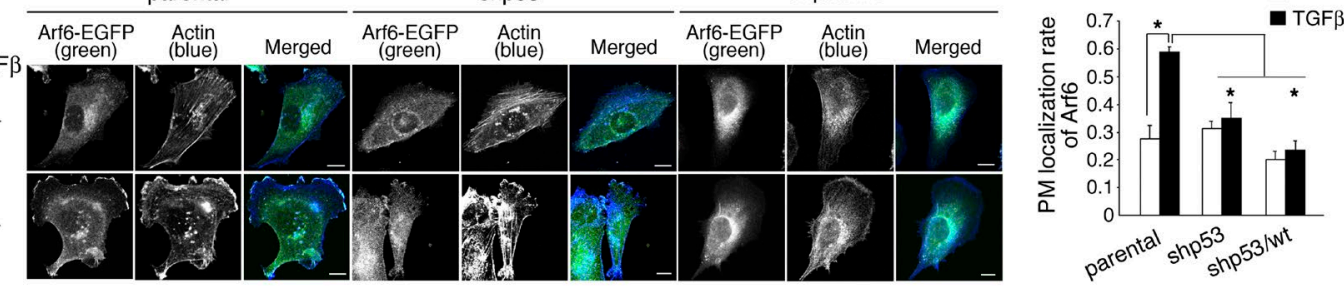

G $\quad$ MDA-MB-231
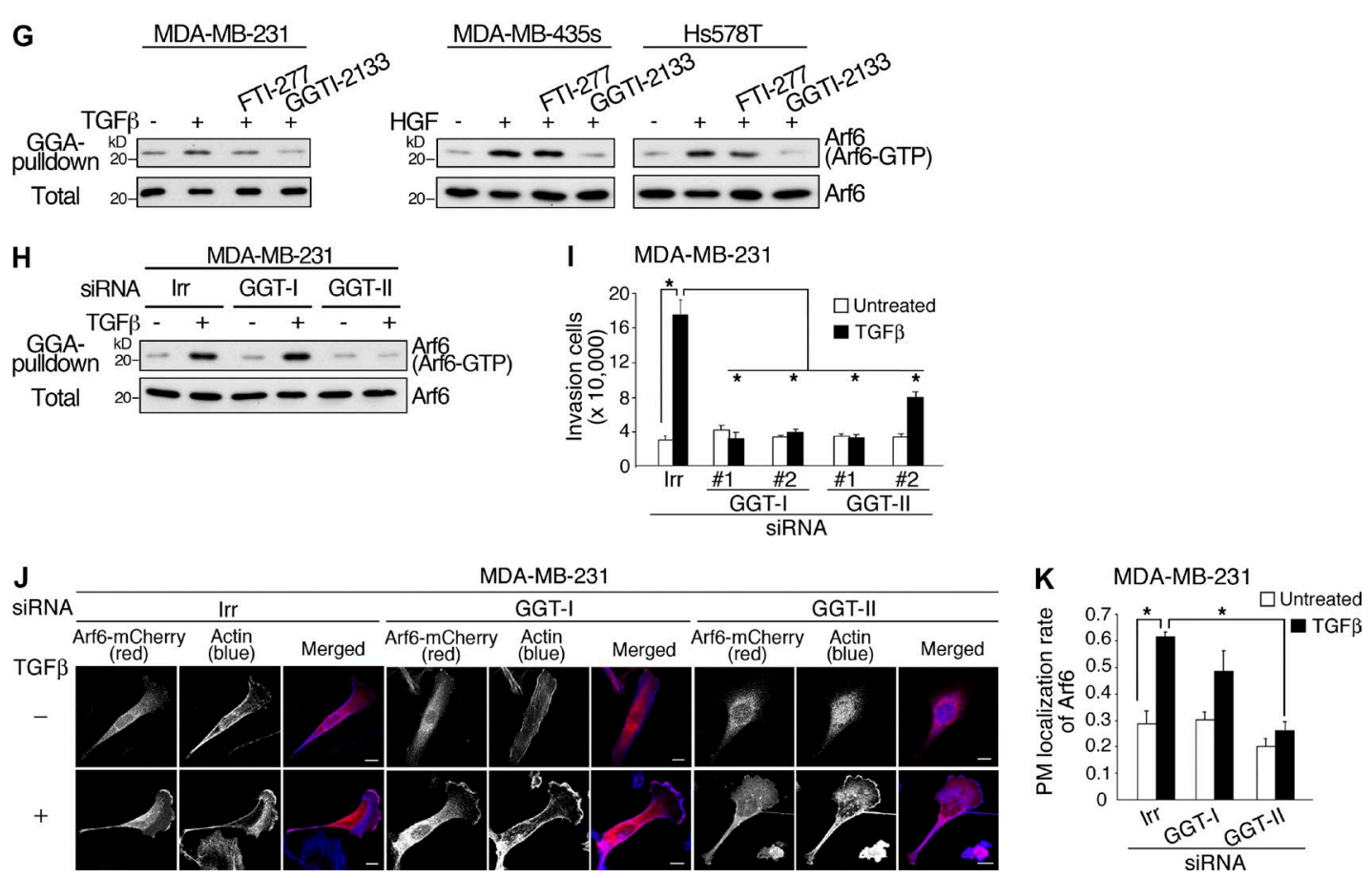

Figure 3. Crucial roles of MVP, GGT-II, and mutant p53 in Arf6 activation. (A-C) Arf6 activation (A), Matrigel invasion (B), and c-Met activation (C) upon TGF $\beta 1$ stimulation were measured using MDA-MB-231 cells preincubated with the indicated inhibitors or DMSO for $16 \mathrm{~h}$. Matrigel invading cells were quantified as described in the Matrigel invasion assay section within Materials and methods $(n=3)$. (D) HGF-induced Arf6 activation was measured in MDA-MB-435s cells and Hs578T cells preincubated with Simvastatin or DMSO for $16 \mathrm{~h}$. (E and F) Subcellular localization of Arf6-EGFP, expressed in MDA-MB-231 cells, and their p53 derivatives was examined before (-) and after (+) 5 min TGF $\beta 1$ stimulation, together with the visualization of F-actin using Alexa Fluor 647-conjugated phalloidin (E). Relative amounts of Arf6-EGFP localized at the cell periphery before and after the stimulation (F) were estimated from >10 cells as described in the Immunofluorescence microscopy section within Materials and methods $(n=2)$. (G-K) Ligand-induced Arf6 activation was measured in breast cancer cells, as indicated, and preincubated with or without $2 \mu M$ FTI-277 or GGTI-2133 for 16 h (G). TGF $\beta$ 1-induced Arf6 activation (H), Matrigel invasion (I), and PM recruitment of Arf6 (J and K) were measured in MDA-MB-231 cells pretreated with siRNAs for GGT-I, GGT-II, or Irr, as indicated. Matrigel invasion activities were measured as in B $(n=3)$, and PM recruitment of Arf6 was estimated as in $F(n=2)$. Representative images are shown from two independent experiments in which $>10$ cells were examined in each experiment. Simvastatin + MVA/MVAP, cells incubated with mevalolactone and MVA 5-phosphate for $6 \mathrm{~h}$ before addition of Simvastatin. The results represent mean \pm SEM. *, $\mathrm{P}<0.001$. Bars, $10 \mu \mathrm{m}$. 

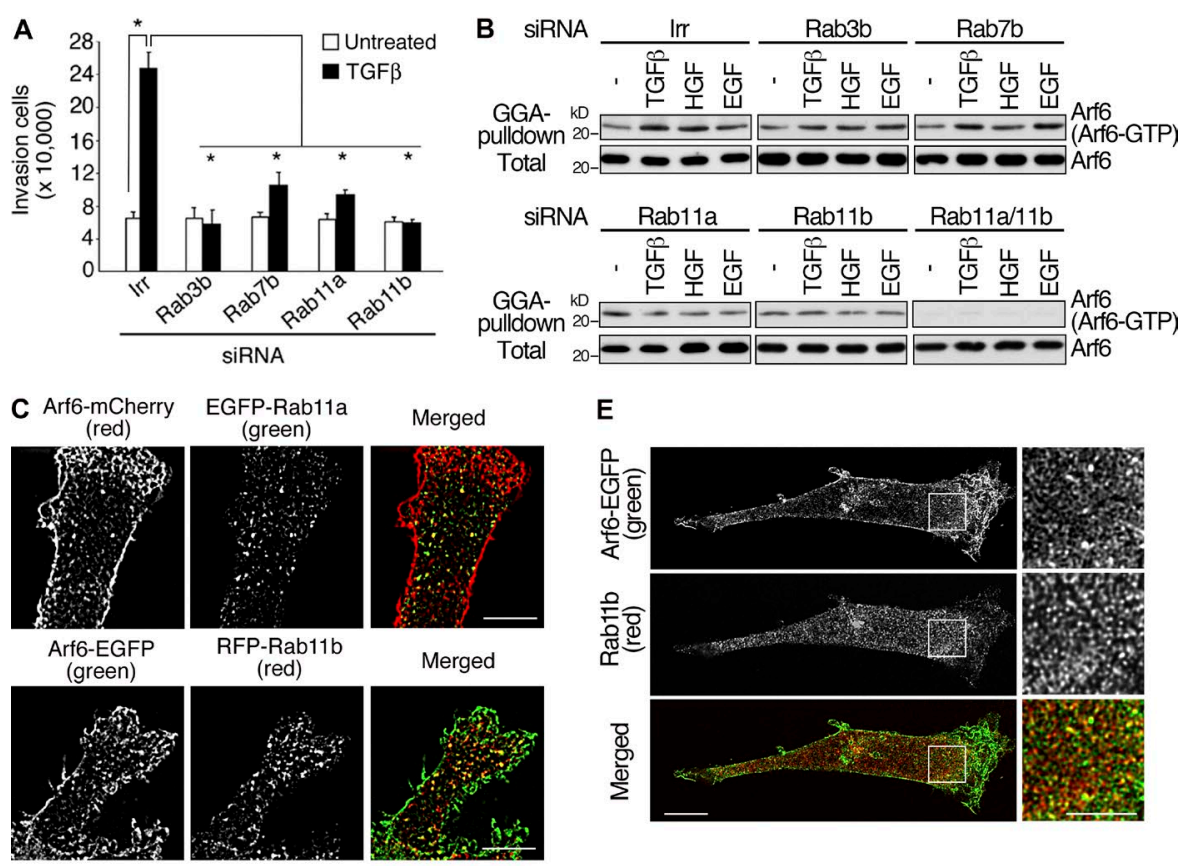

RFP-Rab11b

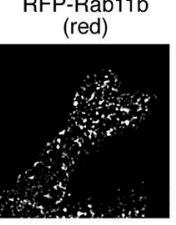

Merged

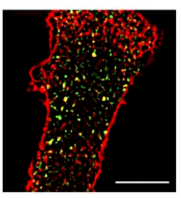

Merged
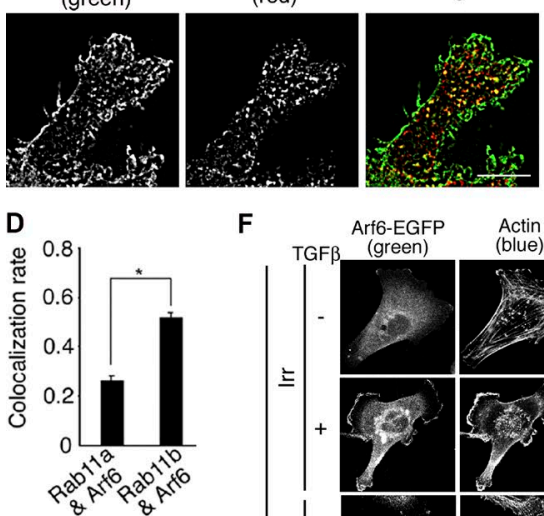

F

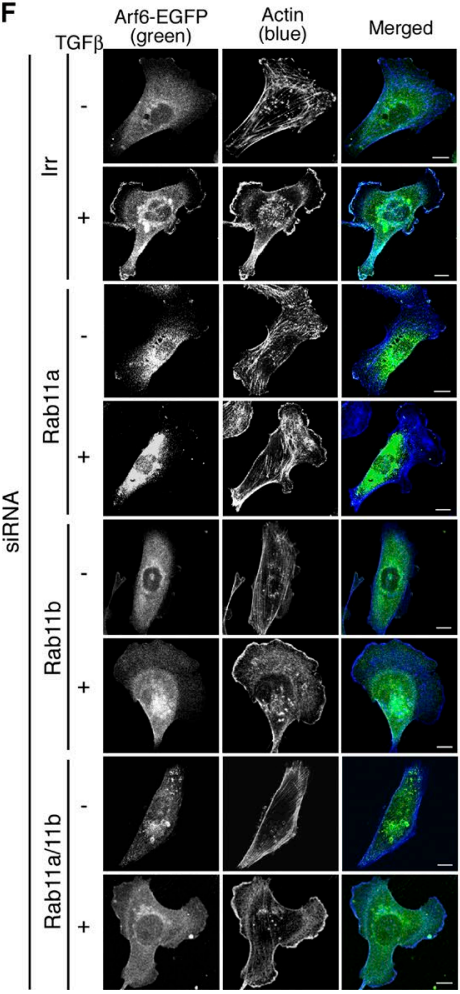

E
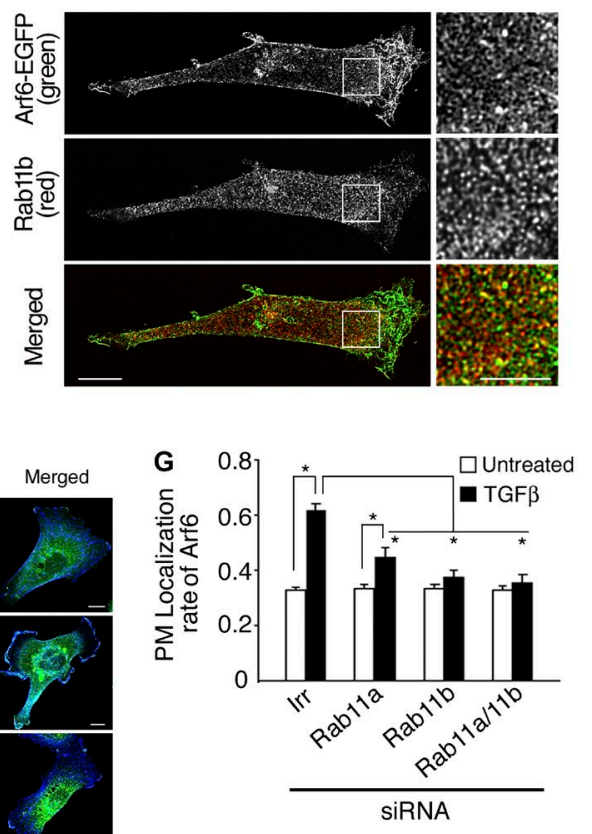

$\mathrm{H}$

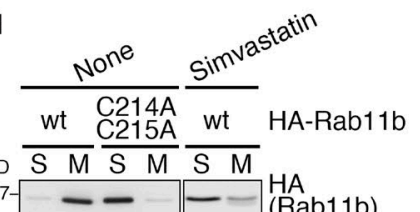

I

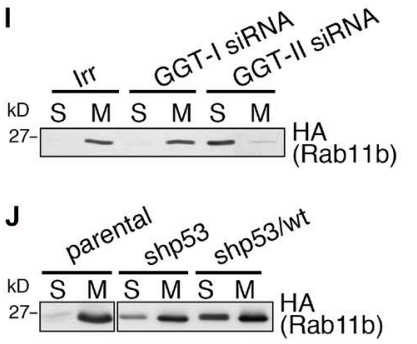

Figure 4. Membrane association of Rabllb is regulated by MVP, GGT-II, and mutant p53, and Rabl $1 \mathrm{~b}$ is responsible for the PM recruitment of Arf6 in MDA-MB-231 cells. (A and B) Ligand-induced Matrigel invasion activities (A) and Arf6 activation (B) were measured in cells pretreated with the indicated siRNAs or Irr. Matrigel invasion activities were measured as described in the Matrigel invasion assay section within Materials and methods. $n=3$. (C and D) Intracellular colocalization of Arf6-mCherry and EGFP-Rabl la (top) or Arf6-EGFP and RFP-Rablib (bottom) was examined using high-resolution SIM (bars, $10 \mu \mathrm{m} ; \mathrm{C})$. Pearson's correlation coefficients of the intracellular colocalization of these proteins, as indicated, were estimated from $>10$ cells as described in the Immunofluorescence microscopy section within Materials and methods. $n=2$ (D). (E) Intracellular colocalization of endogenous Rabl 1 b with Arf6-EGFP was examined using deconvolution microscopy. Enlarged views of the boxed areas are shown on the right. Bars: (right) $5 \mu \mathrm{m}$; (left) $10 \mu \mathrm{m}$. ( $F$ and $G$ ) The PM localization of Arf6-EGFP was examined in cells pretreated with siRNAs for Rabl la, Rab 1 1b, Rab 1 la/l 1 b, or Irr, before (-) and after (+) 5 min TGF $\beta 1$ stimulation. F-actin was visualized using Alexa Fluor 647conjugated phalloidin (F). Relative amounts of Arf6-EGFP localized at the cell periphery (G) were estimated from $>10$ cells as described in the Immunofluorescence microscopy section. $n=2$. $(H-J)$ The membrane association of HA-Rabl $1 \mathrm{~b}$ was measured in cells pretreated with or without Simvastatin for $24 \mathrm{~h}(\mathrm{H})$ or pretreated with siRNAs for GGT-I (siRNA \#1) or GGT-II (siRNA \# 1 ; I) and in parental cells and their $\mathrm{p} 53$ derivatives (J). In $\mathrm{H}$, the Rab $1 \mathrm{lb}$ C214A/C215A mutant was used as a control. wt, wild-type Rab11b. S, soluble fraction. $M$, membrane fraction. Representative images are shown from two independent experiments in which $>10$ cells were examined in each experiment. Bars, $10 \mu \mathrm{m}$. The results represent mean \pm SEM. ${ }^{*}, \mathrm{P}<0.001$.
We also performed time-lapse fluorescence image recording and found that Rab11b is transported together with Arf6 in the cytoplasm before and after stimulation, although Rab11b appeared to separate from Arf6 before Arf6 reaches the PM (Fig. S3 D and Video 1). We confirmed that the colocalization of Rab11b with Arf6 was unaffected, even when different tags were used for each of these small GTPases (Fig. S3 E). We furthermore confirmed that these tagged proteins are not excessively overexpressed by performing immunoblotting analysis (Fig. S3 F).

Using a Triton X114-based fractionation method with MDA-MB-231 cells, we confirmed that Simvastatin dramatically increases the amounts of HA-Rab11b (wt) recovered within the soluble fraction (S), whereas HA-Rab11b in these cells was recovered mostly within the detergent-insoluble membrane fraction (M; Fig. $4 \mathrm{H}$ ). Under this condition, a nongeranylgeranylated mutant of HA-Rab11b (C214A/C215A) was exclusively recovered within the soluble fraction (Fig. $4 \mathrm{H}$ ). Silencing of GGT-II, but not GGT-I, blocked the association of HA-Rab11b with the membrane fraction (Fig. 4 I). Moreover, significant amounts of Rab11b were recovered within the soluble fraction in shp53 cells and shp53/wt cells compared with the parental cells (Fig. 4 J). Furthermore, the originally known function of wt p53 to suppress SREBP activity appeared to be recaptured in our results, in which higher amounts of Rab11b 
were recovered in the soluble fraction in shp53/wt cells than in shp53 cells (Fig. $4 \mathrm{~J}$ ). These results show that MVP and GGT-II are essential for the function of Rab11b and also support the notion that mutant p53 acts to increase the amounts of functional Rab11b proteins, whereas wt p53 acts to limit Rab11b activity and hence limit the activation of Arf6 by external ligands.

Mutant p53 does not affect lipid rafts

MVP leads to the biosynthesis of cholesterol, which, together with other lipids such as sphingolipids, forms discrete heterogenous microdomains termed lipid rafts. Increased amounts of lipid rafts, as well as increased lipid raft localization of EGFR, have been implicated in cancer malignancy ( $\mathrm{Li}$ et al., 2006; Irwin et al., 2011). However, mutant p53 did not appear to be responsible for the enhanced lipid raft localization of these RTKs, nor for the increased amounts of lipid rafts and total cellular cholesterol, at least in MDA-MB-231 cells (Fig. S3, G and H).

\section{Requirement of MVP and GGT-II in ArfG activation originates from a normal \\ cell context}

To clarify whether the requirement for Rab11, as well as for MVP and GGT-II, in Arf6 activation is specific only to some breast cancer cells, we next examined whether these requirements also exist in normal mammary epithelial cells. We used HMLE cells, which are immortalized normal mammary epithelial cells (Elenbaas et al., 2001). The culture medium for these cells contains a basal amount of EGF to maintain their viability, which prevented us from starving the cells of EGF. We instead found that silencing of Rab11b greatly reduces Arf6 activity and causes the cytoplasmic redistribution of Arf6 in HMLE cells, even in the presence of EGF (Fig. 5, A and B). Silencing of Rab1 la also significantly reduced Arf6 activity, although to a lesser extent than that by Rab11b silencing (Fig. 5 A). HMLE cells were found to express Rab11c (Fig. S4 A). Silencing of Rab11c also reduced Arf6 activity, again to a lesser extent than that by Rab11b silencing (Fig. $5 \mathrm{~A}$ ). Therefore, although all Rab11 family members appear to be involved in the processes activating Arf6, Rab11b appears to play the major role in HMLE cells. We also confirmed that cell viability was not affected by the silencing of these mRNAs (Fig. S4, B-D). Moreover, a similar cytoplasmic redistribution of Arf6 was observed by treatment of HMLE cells with Simvastatin (Fig. 5 C). Therefore, the requirement for MVP and Rab11 in Arf6 activation is likely to occur also in a normal cell context.

MVP and Rab11b are essential for Arf6driven metastasis

We then validated the requirement for Rab11b in metastasis. The shRNA-mediated silencing of Rab1lb in MDA-MB-231 cells, expressing a firefly luciferase reporter, effectively blocked lung metastasis in nude mice, in which the cells were originally injected into tail veins (Fig. 6, A and B; and Fig. S4, E and F). This silencing did not affect cell growth in vitro but reduced cell invasion in vitro (Fig. S4, G and H). Simvastatin also blocked the lung metastasis of MDA-MB-231 cells in vivo without affecting cell proliferation in vitro (Fig. 6, C and D; and Fig. S4, I and J), as previously demonstrated using other cell lines (Shibata et al., 2004). However, inhibitors of GGT, which can be safely administered to animals for long periods of time, are not available. Collectively, these results indicated that MVP and Rab11b, which is a substrate of GGT-II, are essential for the metastasis of breast cancer cells, in which metastatic activity is primarily driven by the Arf6 pathway.

Blocking the ArfG pathway effectively decreases the drug resistance of breast cancer cells

As mentioned earlier, the expression of mesenchymal genes in breast cancer cells is closely associated with their acquisition of drug resistance. The Arf6 pathway includes mesenchymalspecific EPB41L5, which is expressed in MDA-MB-231 cells and MDA-MB-435s cells at high levels (unpublished data). A fundamental function of EPB41L5 is to down-regulate E-cadherin (Hirano et al., 2008); the down-regulation of Ecadherin is a hallmark feature that leads to anoikis resistance and may thereby also lead to the drug resistance of cancer cells (Frisch et al., 2013). We hence investigated whether EPB41L5, as well as the Arf6 pathway, contributes to the drug resistance of breast cancer cells. Gemcitabine is a cytidine analogue, and Temsirolimus is an inhibitor of mammalian target of rapamycin activity (Maring et al., 2005; Grunt and Mariani, 2013). We found that knockdown of EPB41L5 by its specific siRNAs significantly improves the sensitivities of MDA-MB-231 cells and MDA-MB-435s cells to Gemcitabine and Temsirolimus (Fig. 7, $A$ and B). We then found that Simvastatin also significantly improves the drug sensitivities of these cells (Fig. 7, C and D). Such effects were observed at concentrations of $10 \mathrm{nM}$ or lower for Simvastatin, as well as for Gemcitabine and Temsirolimus. However, such improvement by Simvastatin was not at all observed in MDA-MB-468 cells and MCF7 cells (Fig. S5, A and B), which do not overexpress components of the Arf6 pathway (Hashimoto et al., 2004a; Onodera et al., 2005). The expression of EPB41L5 in these cells is almost undetectable (unpublished data). Furthermore, the silencing of GGT-II and Rab11b each also enhanced the drug sensitivities of MDA-MB-231 cells and MDA-MB-435s cells but not MDA-MB-468 cells and MCF7 cells (Fig. 7, A and B; and Fig. S5, C and D), even though MDA-MB-468 cells and MCF7 cells expressed GGT-II and Rab11b at levels comparable to those in MDA-MB-231 cells and MDA-MB-435s cells (Fig. S5, E and F). These results indicated that the Arf6-based mesenchymal pathway may significantly contribute to the promotion of the drug resistance of breast cancer cells. Consistent with this notion, these results demonstrated that statins, as well as blocking the activities of GGT-II and Rab11b, can effectively decrease the drug resistance of breast cancer cells if they overexpress components of the Arf6-based mesenchymal pathway.

MVP and the Arf6 pathway cooperatively promote the poor outcome of patients

We finally investigated the clinical relevance of the possible cooperation between MVP and the Arf6 pathway in breast cancer malignancy. Overexpression of HMGCR (encoding HMGCR) in primary breast tumors statistically correlates with the poor overall survival of patients (Freed-Pastor et al., 2012). We previously analyzed the Cancer Genome Atlas RNASeq dataset on primary breast tumors $(n=970$; Cancer Genome Atlas Network, 2012) and showed that the simultaneous high expression of mRNAs (top 33\%) of all components of the Arf6 pathway (i.e., mRNAs for GEP100, Arf6, AMAP1, EPB41L5, and $E G F R$ and/or $c$-Met) correlates with the poor overall survival of patients with a p-value of 0.0419 (unpublished data). In the same dataset, high expression of HMGCR (top 33\%) 
A
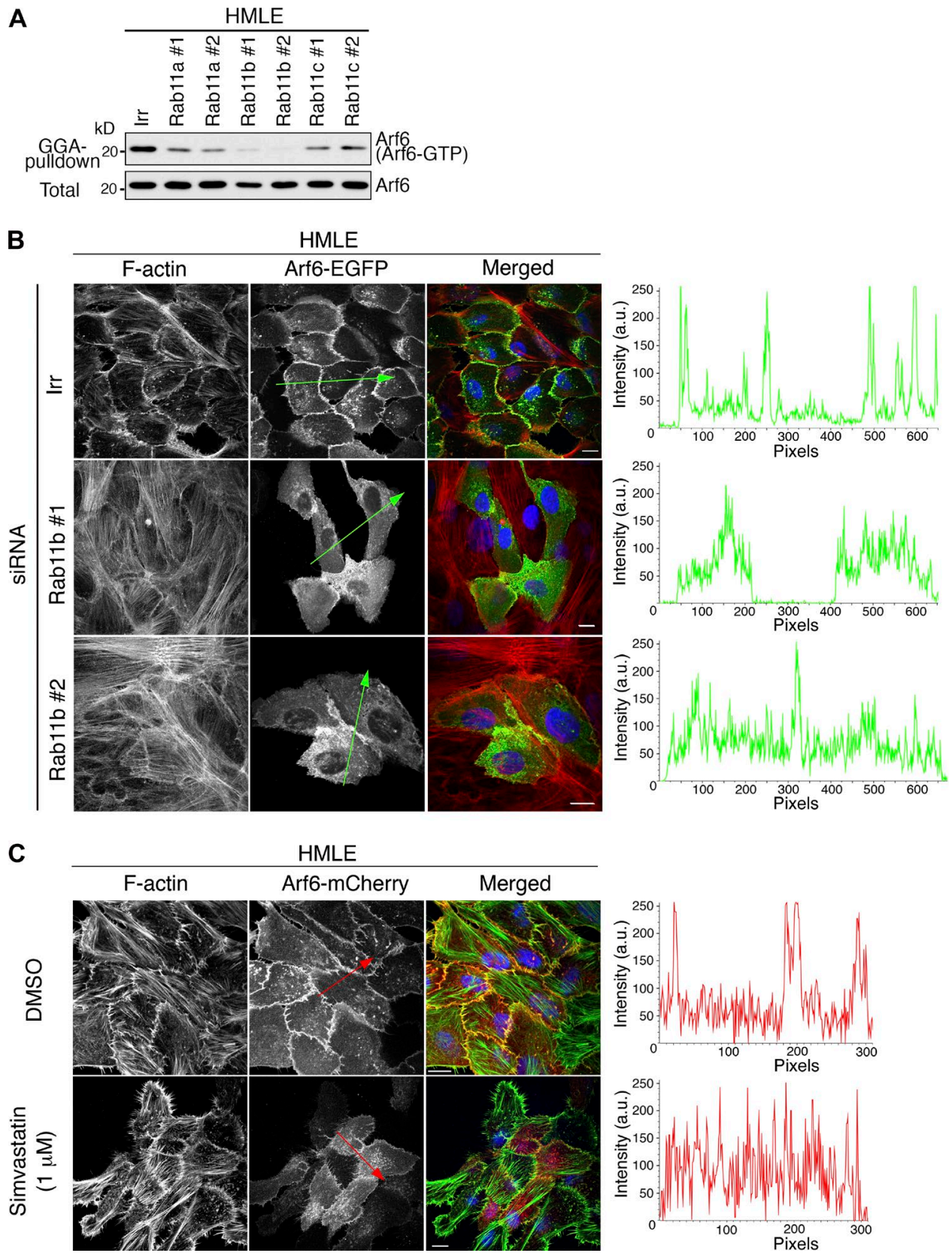

Figure 5. Requirement for MVP and Rab1 1 in the PM recruitment and activation of Arf6 in HMLE cells. (A) Arf6 activities of cells pretreated with siRNAs for Rabl 1a, Rab 1 1b, Rab 1 lc, or Irr and maintained in their growth medium were measured. (B and C) Subcellular localization of Arf6-EGFP or Arf6mCherry was examined in cells pretreated with siRNAs for Rabl $1 \mathrm{~b}$ or Irr (B) or preincubated with Simvastatin or DMSO for $24 \mathrm{~h}$ (C) and maintained in growth medium. F-actin was visualized using Alexa Fluor 568- (B) or Alexa Fluor 488-conjugated (C) phalloidin. Fluorescence intensities along the green arrows $(B)$ and the red arrows $(C)$ are shown on the right. Each experiment was performed at least twice, and representative images from $>10$ cells then examined are shown. Bars, 10 m. a.u., arbitrary units.

indeed correlated with poor overall survival (Fig. 7 E). We then found that co-overexpression of $H M G C R$ with mRNAs for all components of the Arf6 pathway exhibits a stronger correlation (Fig. 7 F). Moreover, high expression of EPB41L5 (top 33\%) on its own was previously found to sufficiently correlate with poor overall survival (p-value of 0.0242; unpublished data). Notably, co-overexpression of EPB41L5 and HMGCR tightly correlated with poor overall survival, with a much higher correlation value than high EPB41L5 expression or high HMGCR expression alone (Fig. $7 \mathrm{G}$ ). Thus, consistent with our results obtained using cultured cells, overexpression of components of the Arf6- based mesenchymal pathway and enhancement of MVP activity appear to cooperatively promote breast cancer malignancy.

\section{Discussion}

In this paper, we show that MVP is essential for the activation of Arf6 by external ligands, particularly through the activity of GGT-II and its substrate Rab11 both in normal cells and cancer cells. However, components of the Arf6-based pathway are often abnormally overexpressed in different cancer cells, and 
A
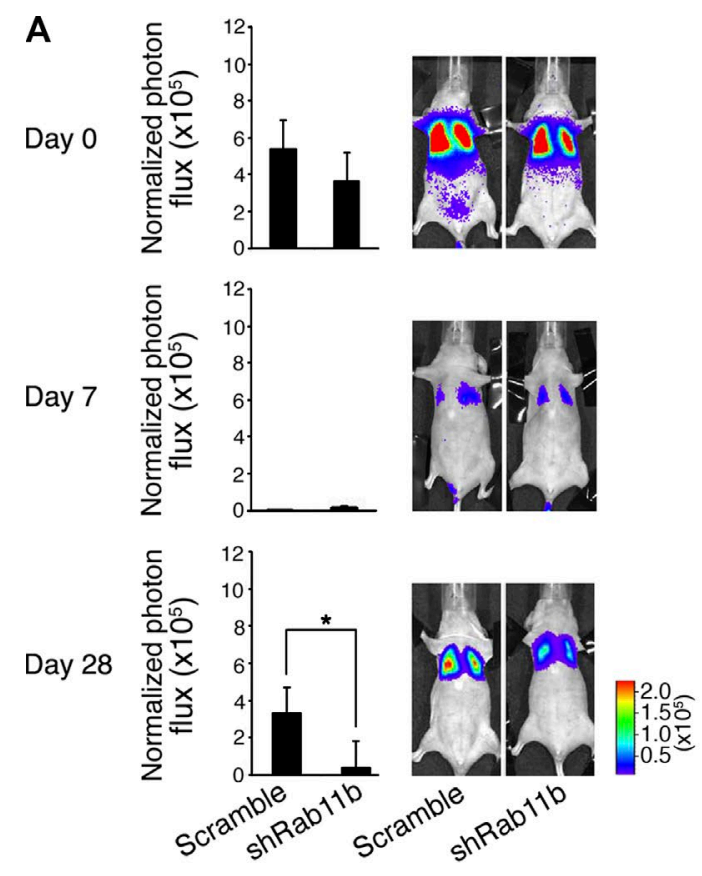

B
C

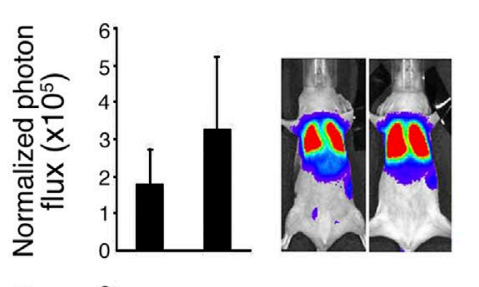

Day 7

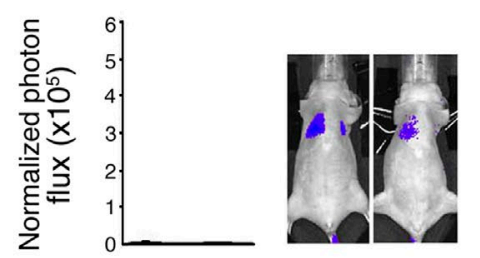

Day 28

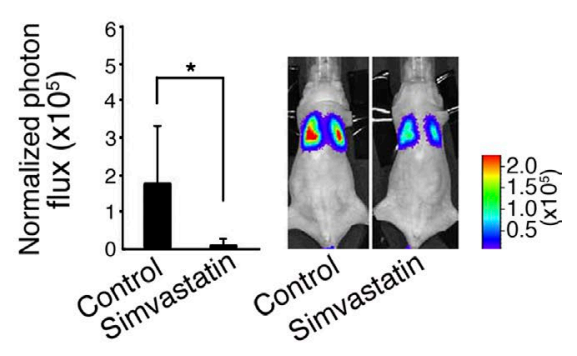

D

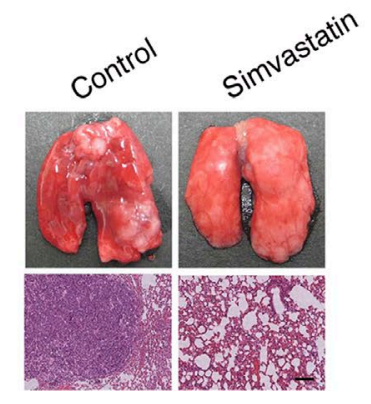

Figure 6. Requirement for MVP and Rabl1b in cancer metastasis. (A-D) Lung metastases of MDA-MB-231 cells expressing a luciferase reporter were measured after their injection into the tail veins of nude mice. Cells were transfected with an shRNA plasmid (to silence Rabl 1 b) or a control vector (Scramble; A and B) or were pretreated with Simvastatin or a control solution for $2 \mathrm{~d}$ before the injection (C and D). In C and D, mice received Simvastatin or a control solution, as indicated, every day after the injection. In A and C, bioluminescence intensities from the chests of the injected mice were measured on the indicated days. Results are shown as mean \pm SEM. $n=5 .{ }^{*}, P<0.05$. Representative images of the mice are shown on the right. In $B$ and $D$, representative whole images of the lungs (top) and hematoxylin and eosin staining of lung sections (bottom) $28 \mathrm{~d}$ after the injection are shown. Bars, 100 mm.

such overexpression is crucial to promote invasion and metastasis to be statistically associated with the poor outcome of patients (Hashimoto et al., 2004a, 2006, 2016; Onodera et al., 2005; Morishige et al., 2008; Menju et al., 2011; Kinoshita et al., 2013; Sato et al., 2014). Based on these facts, we here demonstrated that the newly discovered link of MVP to Arf6 activation is critical for malignancy of breast cancer cells that overexpress the Arf6 pathway. Like Arf6 and its signaling proteins, RTKs are also frequently overexpressed in different breast cancer cells, which is associated with the poor outcome of patients (Ocaña et al., 2013; Elster et al., 2015). It is hence conceivable that the enhancement of MVP activity, such as by mutant $\mathrm{p} 53$, greatly assists in the efficient activation of overexpressed Arf6 and its signaling pathway under enhanced RTK signaling through enhancement of the geranylgeranylation of Rab11, which then facilitates the intracellular trafficking of Arf6 proteins to the PM to be activated by RTKs.

Our results suggest that co-overexpression of EPB41L5 and $H M G C R$ mRNAs provides a biomarker predictive for breast cancer cells that can be highly reactive to MVP inhibition. Immunohistochemical detection of their protein products might also show similar results, as these mRNAs appear structurally to belong to "strong" mRNAs that are immediately translated into proteins upon transcription (De Benedetti and Graff, 2004). The 5-yr survival rates of breast cancer patients have reached $>80 \%$ in several medically advanced countries (Coleman et al., 2008). Interestingly, effects of the possible cooperation of enhanced MVP activity and the overexpressed Arf6 pathway appear to manifest 5 yr or so after the diagnosis (Fig. 7, F and G). Activities of MVP change dynamically under various physiological conditions, such as by cholesterol intake and estrogen levels (Goldstein and Brown, 1990; Faulds et al., 2012). However, TP53 mutations may account for only a small population of the high $H M G C R$ expression group of primary breast tumors (Fig. S5, G and H), despite the fact that TP53 mutations are very frequent in breast cancer cells with highly aggressive phenotypes, i.e., the basal-like genotype cells (80\%; Cancer Genome Atlas Network, 2012). In this regard, it should be noted that TP53 mutations are infrequent in other types of breast cancer cells, such as the luminal A genotype (12\%) and the luminal B genotype (29\%; Cancer Genome Atlas Network, 2012). Thus, it would be interesting to investigate the types of 
A MDA-MB-231

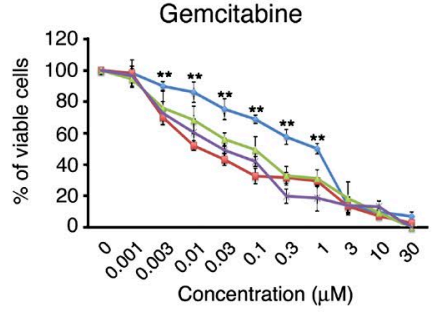

B MDA-MB-231

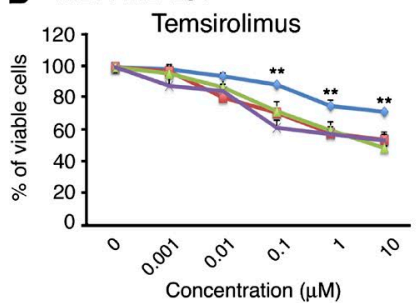

C MDA-MB-231

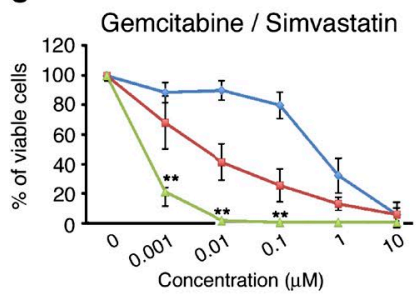

D MDA-MB-231

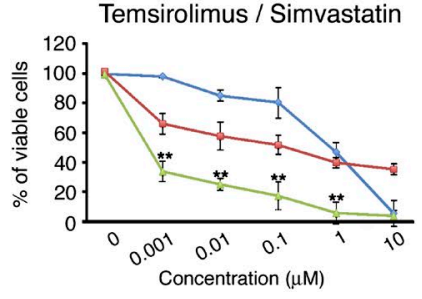

MDA-MB-435s

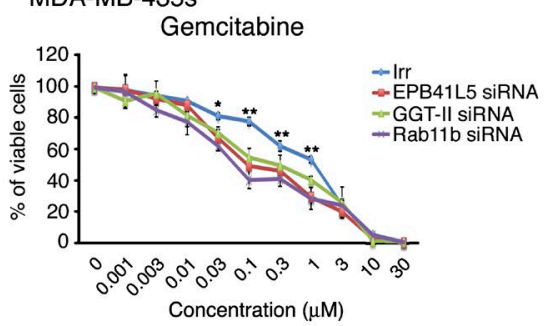

MDA-MB-435s

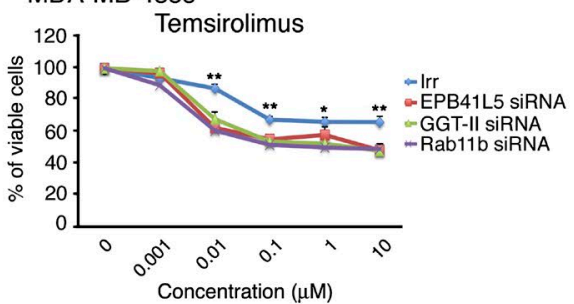

MDA-MB-435s

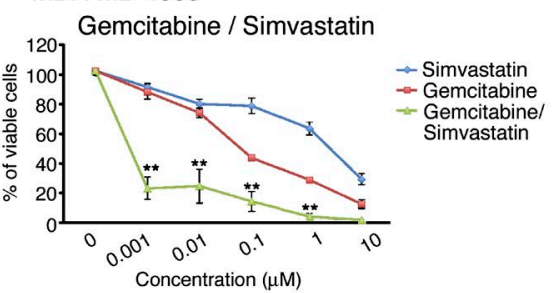

MDA-MB-435s

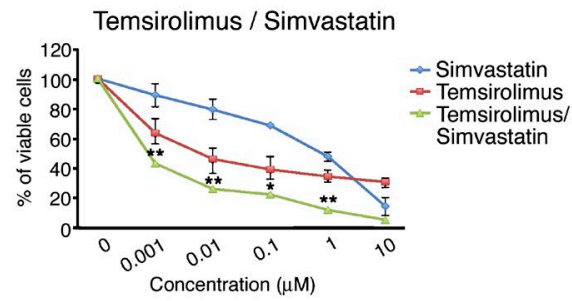

Concentration $(\mu \mathrm{M})$
E

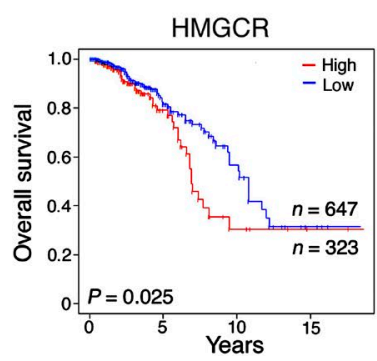

F GEP100/Arf6/AMAP1/EPB41L5/

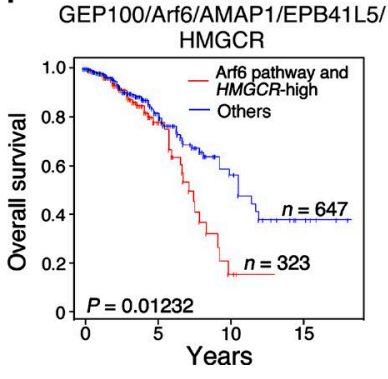

G

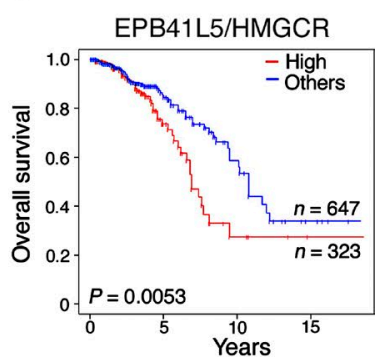

Figure 7. MVP and the Arf6 pathway cooperatively promote cancer malignancy. (A and B) MDA-MB-231 or MDA-MB435s cells, pretreated with siRNAs for EPB4 1L5, GGT-II, $R a b 11 b$, or Irr, were incubated with the indicated doses of Gemcitabine (A) and Temsirolimus (B) for $72 \mathrm{~h}$, and their viabilities were then measured as described in the Cell lines section within Materials and methods. (C and D) Breast cancer cells were incubated with Gemcitabine (C) or Temsirolimus (D), with or without Simvastatin, as indicated. After incubation for $72 \mathrm{~h}$, their viabilities were measured. At each point, concentrations of Simvastatin were equal to those of Gemcitabine or Temsirolimus. Each experiment was performed at least twice. (A-D) The results represent mean \pm SEM from three independent experiments measuring 3 wells per condition in each experiment. $(E-G)$ High expression levels (top 33\%) of HMGCR mRNA alone $(E)$, together with high expression levels of mRNAs of components of the Arf6 pathway $(F)$, or together with high expression levels of EPB4 $1 L 5$ mRNA (G) in primary breast tumors were examined with regard to the poor overall survival of patients using the Cancer Genome Atlas RNASeq dataset $(n=970)$. Others, patients without the simultaneous high expression of HMGCR and Arf6 pathway component mRNAs (F) or patients with expression level combinations of EPB4 $1 L 5$ and HMGCR other than EPB4 1L5-high and HMGCR-high (G). The survival rates of each group are shown as Kaplan-Meier curves, in which p-valves represent the results of the log-rank test. ${ }^{*}$, $\mathrm{P}<0.05 ; * *, \mathrm{P}<0.01$. nutritional as well as hormonal conditions of patients that may respond well to the inhibition of MVP and GGT-II. However, it should also be noted that animal experiments revealed that statins administrated orally selectively accumulate in the liver (Duggan et al., 1989; Vickers et al., 1990; Nezasa et al., 2002), whereas statins can be delivered to target organs by other methods, including intraarterial infusion, as well as direct infusion into mammary ducts in the case of breast cancer.

We recently found that ccRCCs also frequently overexpress components of the Arf6 pathway, overexpression which is tightly associated with the poor outcomes of patients (Hashimoto et al., 2016). In ccRCCs, however, Arf6 is activated by EFA6, but not GEP100, under G protein-coupled receptors (Hashimoto et al., 2016). Consistently, we found that statins were not highly effective in reducing the drug resistance of ccRCC cell lines (unpublished data). Moreover, we still do not know the precise molecular mechanisms as to how EPB41L5 and also the Arf6-based pathway enhance the drug resistance of cancer cells. It is possible that the involvement of EPB41L5 and the Arf6 pathway, as well as the enhanced activities of MVP promoting Arf6 activation, in drug resistance depends on the cell context. The degree of involvement might also vary depending on the types of cancers and on the different genomic mutations in different cancer cells. Therefore, a detailed understanding of these mechanisms will be necessary to further ensure the effective use of MVP inhibitors in clinical settings.

In conclusion, our results suggested that blocking the activities of MVP, particularly blocking GGT-II, may effectively 
kill cancer cells that overexpress the Arf6-based mesenchymal pathway (i.e., the responders) when appropriately combined with other therapeutics and perhaps also with particular patient conditions and genome status of cancer cells. Blocking these enzymatic activities of the responder cells on their own may also effectively block their motility and invasiveness. Furthermore, consistent with the reported functions of statins (Yeganeh et al., 2014), such blockage is expected to effectively inhibit tumor angiogenesis, as overexpressed Arf6 and AMAP1 are also essential for this process (Hashimoto et al., 2011). We hence propose that clinical usefulness of statins for cancer therapy should be reevaluated using the biomarkers that we have identified in this paper to be predictive of the responders of cancer cells. In addition to statins, GGT-II inhibitors that can be administered safely to humans may have high potential to be developed as cancer therapeutics (Berndt et al., 2011; Zhou et al., 2015), although to date, the development of safe GGT-II inhibitors has been unsuccessful because of the serious side effects of the conventional method of GGT inhibition.

\section{Materials and methods}

\section{Cell lines}

MDA-MB-231, MDA-MB-435s, Hs578T, MDA-MB-468, and MCF7 cells were obtained from ATCC. MDA-MB-231 cells were maintained in a 1:1 mixture of DMEM (Invitrogen)/RPMI 1640 (Invitrogen), supplemented with 10\% FCS (HyClone) and 5\% NU serum (BD). MDA-MB-435s, Hs578T, MDA-MB-468, and MCF7 cells were maintained as instructed by ATCC. HEK293T FT cells were purchased from Invitrogen and maintained according to the manufacturer's instructions. Plat-E cells were a gift from T. Kitamura (Tokyo University, Tokyo, Japan) and maintained in DMEM containing 10\% FCS. HMLE cells were a gift from R.A. Weinberg (Massachusetts Institute of Technology, Cambridge, MA) and cultured in mammary epithelial cell growth medium (Lonza). No antibiotics were used in our cell cultures to avoid latent contamination with mycoplasma.

To generate MDA-MB-231 cells stably expressing Arf6-EGFP or Arf6-mCherry, cells were retrovirally transduced with pCX4-blast/ Arf6-EGFP or pCX4-blast/Arf6-mCherry and selected with $20 \mu \mathrm{g} / \mathrm{ml}$ Blasticidin S (Invitrogen).

For ligand stimulation, cells were prestarved for FCS for $16 \mathrm{~h}$ and then incubated with $2 \mathrm{ng} / \mathrm{ml}$ TGF $\beta 1$ (R\&D Systems), $10 \mathrm{ng} / \mathrm{ml}$ HGF (PeproTech), or $10 \mathrm{ng} / \mathrm{ml}$ EGF (PeproTech) in the absence of FCS for the indicated times before being subjected to analyses.

Cell viabilities were measured using a cell counting kit (CCK-8; Dojindo) according to the manufacturer's instructions. Protein concentration of cell lysates was measured using a bicinchoninic acid protein assay kit (Thermo Fisher Scientific).

\section{Chemicals}

The following chemicals were from Sigma-Aldrich: Simvastatin (S6196), Mevastatin (M2537), 6-fluoromevalonate (F2929), GGTI2133 (G5294), FTI-277 (F9803), DL-mevalolactone (M4667), and DL-MVA 5-phosphate (79849). All other chemicals were purchased from Sigma-Aldrich or Wako Pure Chemical Industries, unless otherwise stated.

\section{Antibodies and immunoblotting}

Affinity-purified rabbit polyclonal antibodies against GEP100 and AMAP1 were as described previously (Onodera et al., 2005; Morishige et al., 2008). A rabbit polyclonal antibody against EPB41L5 was raised against a GST-fused peptide corresponding to amino acids 541-733 of EPB41L5. The resulting serum was adsorbed with GST and then affinity purified using the antigen peptide before use. Other antibodies were purchased from commercial sources as follows: mouse monoclonal antibodies against Arf6 (Santa Cruz Biotechnology, Inc.), p53 (Cell Signaling Technology), V5-tag (Invitrogen), Flotillin (BD), and $\beta$ actin (EMD Millipore); and rabbit polyclonal antibodies against GGT-I and GGT-II (Santa Cruz Biotechnology, Inc.), Rab11b (immunoblotting, Cell Signaling Technology; immunostaining, Abgent), c-Met, Tyr1234/1235-phosphorylated c-Met, EGFR, Tyr1086-phosphorylated EGFR, Gab1, Tyr307-phosphorylated Gab1, Akt, Ser473-phosphorylated Akt, Smad2, Ser465/467-phosphorylated Smad2, and Rab11b (Cell Signaling Technology). Donkey antibodies against rabbit and mouse IgGs, each conjugated with horseradish peroxidase, were from Jackson ImmunoResearch Laboratories, Inc. Immunoblotting analysis was performed using detection reagents (ECL Western; GE Healthcare) as described previously (Hashimoto et al., 2004a).

\section{Plasmids}

pEGFP-Rab11a and pmRFP-Rab11b were described previously (Matsui et al., 2011). The plasmid encoding Arf6-EGFP was constructed as follows. The NheI-NotI fragment of Arf6-EGFP isolated from the pEGFP-N1-Arf6 plasmid (Hashimoto et al., 2004a) was blunted and then ligated into the blunted EcoRI site of the pCX4-blast vector (a gift from T. Akagi, KAN Research Institute, Inc., Kobe, Japan). The plasmid encoding Arf6-mCherry was constructed as follows. The HindIIINotI fragment of mCherry was isolated from the pmCherry-N1 vector (a gift from N. Mochizuki, National Cardiovascular Center Research Institute, Osaka, Japan) and inserted into the HindIII-NotI site of the pCX4-Arf6-EGFP plasmid that was digested with HindIII and NotI to remove the EGFP fragment. HA-Rab11b was generated by PCR and inserted into the BamHI sites of the pCX4 vector. HA-Rab11b C214A/ C215A was obtained by PCR site-directed mutagenesis, using the plasmid HA-Rab11b as a template, and then blunted and ligated. Oligonucleotides used for the PCR reactions are shown in Table S1.

\section{siRNA}

siRNA-mediated gene silencing was performed as described previously (Hashimoto et al., 2004a; Morishige et al., 2008). In brief, cells were transfected with $50 \mathrm{nM}$ siRNA oligonucleotide duplexes using Lipofectamine 2000 or Lipofectamine RNAi Max (Invitrogen) according to the manufacturer's instructions and incubated for $48 \mathrm{~h}$, unless otherwise described, before being subjected to assay. Duplex oligonucleotides were chemically synthesized and purified by Japan BioService. Two different sequences were used for each target, except for Arf6, GEP100, AMAP1, and EPB41L5, for which we have previously confirmed the specificity of the oligonucleotides (Hashimoto et al., 2004a; Onodera et al., 2005; Morishige et al., 2008). The nucleotide sequences used are shown in Table S2.

For Rab-RNAi screening, siRNA libraries (targeting 122 genes; Human siGENOME SMARTpool siRNA libraries for cell membrane trafficking; GE Healthcare) were used. An siRNA duplex with an irrelevant sequence (Irr; 5'-GCGCGCUUUGUAGGAUUCG-3') was also purchased from GE Healthcare.

\section{p53 manipulation}

For the stable silencing of endogenous mutant p53, pLKO.1-purobased recombinant lentiviruses were generated according the method described previously (Moffat et al., 2006). In brief, shRNAs against p53 were purchased from an shRNA library (TRCN0000342261; Sigma Mission; Sigma-Aldrich), and a control scramble shRNA in pLKO.1-puro (1864; Addgene) was transfected into 293FT cells, 
together with the envelope plasmid pMD2.G (12259; Addgene) and the packaging plasmid psPAX2 (12260; Addgene) using Lipofectamine LTX (Invitrogen) according to the manufacturer's instructions. $48 \mathrm{~h}$ after transfection, the cultured supernatants were harvested and filtered through $0.45-\mu \mathrm{m}$ filters (Advantec), and the resultant lentivirus preparations were then applied onto target cells in the presence of $8 \mu \mathrm{g} / \mathrm{ml}$ Polybrene. After $24 \mathrm{~h}, 1.25 \mu \mathrm{g} / \mathrm{ml}$ puromycin was added to the culture for $1 \mathrm{wk}$ to select infected cells.

For generation of cells stably expressing recombinant p53, pBabe-hygro vector-based retroviruses (Morgenstern and Land, 1990) were generated as follows. Plasmids encoding the V5-tagged normal p53 protein and mutant p53 proteins $(\mathrm{R} 175 \mathrm{H}, \mathrm{R} 249 \mathrm{~S}, \mathrm{R} 273 \mathrm{H}$, and R280K) were purchased (22945, 22936, 22935, 22934, and 22933, respectively; Addgene). A cDNA encoding a trans-activation-deficient p53 protein (L22Q/W23S/W53Q/F54S; p53 txn-dead) was generated by PCR-based mutagenesis, and these mutations were then introduced into the R280K construct. The oligonucleotide primers that were used are listed in Table S1. DNA fragments encoding these p53 constructs were then each ligated into the SnaB1 site of the pBabe-Hygro vector. Recombinant retroviruses were generated using Plat-E packaging cells and the pGP-Ampho and pE-Ampho plasmids (Takara Bio Inc.; Akagi et al., 2003). $24 \mathrm{~h}$ after the infection of these plasmids into cells, infected cells were selected by the addition of $200 \mu \mathrm{g} / \mathrm{ml}$ hygromycin (Wako Pure Chemical Industries) and $1.25 \mu \mathrm{g} / \mathrm{ml}$ puromycin. During these experiments, we observed that the expression of normal p53 in MDA-MB-231 cells using other vectors, such as the pLenti6-based lentiviral vector (22945; Addgene) and the pcDNA vector (Invitrogen), caused immediate cell senescence or death.

\section{GST-GGA pull down and protein coprecipitation}

Arf6 activities were measured using the GST-GGA pull-down assay, as described previously (Morishige et al., 2008). In brief, cells were lysed on ice with GGA buffer ( $1 \%$ Triton X-100, $0.5 \%$ sodium deoxycholate, $0.1 \%$ SDS, $50 \mathrm{mM}$ Tris- $\mathrm{HCl}, \mathrm{pH} 7.4,100 \mathrm{mM} \mathrm{NaCl}, 2 \mathrm{mM}$ $\mathrm{MgCl}_{2}, 10 \%$ glycerol, $1 \mathrm{mM}$ sodium orthovanadate $\left[\mathrm{Na}_{3} \mathrm{VO}_{4}\right], 1 \mathrm{mM}$ PMSF, $5 \mu \mathrm{g} / \mathrm{ml}$ aprotinin, $2 \mu \mathrm{g} / \mathrm{ml}$ leupeptin, and $3 \mu \mathrm{g} / \mathrm{ml}$ pepstatin A). Lysates were clarified by centrifugation at $15,000 \mathrm{~g}$ for $10 \mathrm{~min} .300 \mu \mathrm{g}$ of cell lysates were incubated with $50 \mu \mathrm{g}$ GST-GGA bound to glutathione-Sepharose beads (GE Healthcare) for $45 \mathrm{~min}$. The beads were then washed three times with $1 \mathrm{ml}$ GGA buffer; proteins bound to the beads were eluted into $30 \mu \mathrm{l}$ SDS sample buffer, separated by SDS-PAGE ( $15 \%$ gel), and subjected to immunoblotting using an Arf6 antibody. Total levels of Arf6 in the starting lysates were assayed by immunoblotting. Protein coprecipitation assays using appropriate antibodies were performed as described previously (Morishige et al., 2008). In brief, cells were lysed in radioimmunoprecipitation assay buffer (1\% Nonidet P-40, $1 \%$ deoxycholate, $0.1 \%$ SDS, $20 \mathrm{mM}$ Tris-HCl, pH 7.4, $150 \mathrm{mM}$ $\mathrm{NaCl}, 5 \mathrm{mM}$ EDTA, $1 \mathrm{mM} \mathrm{Na} \mathrm{VO}_{4}, 1 \mathrm{mM}$ PMSF, $5 \mu \mathrm{g} / \mathrm{ml}$ aprotinin, 2 $\mu \mathrm{g} / \mathrm{ml}$ leupeptin, and $3 \mu \mathrm{g} / \mathrm{ml}$ pepstatin A). $1 \mathrm{mg}$ of each cell lysate was then incubated with the appropriate antibodies coupled with protein ASepharose beads. The beads were washed three times with $1 \mathrm{ml}$ radioimmunoprecipitation assay buffer, and proteins precipitated with these antibodies were separated by SDS-PAGE ( $8 \%$ gel) and then subjected to immunoblotting using antibodies against the proteins of interest.

\section{Matrigel invasion assay}

The Matrigel chemoinvasion assay was performed using Matrigel chambers (Biocoat; BD) as described previously (Morishige et al., 2008). In brief, $10^{5}$ cells were seeded on the upper wells of 24-well chambers in the absence of serum, in which the lower wells were filled with $2 \mathrm{ng} / \mathrm{ml}$ TGF $\beta 1,10 \mathrm{ng} / \mathrm{ml} \mathrm{HGF,} 10 \mathrm{ng} / \mathrm{ml} \mathrm{EGF}$, or 10\% FCS. After incubation for $18 \mathrm{~h}$, cells were fixed in $4 \% \mathrm{PFA}$, and the number of cells that transmigrated through the chamber filter $(6.4 \mathrm{~mm}$ in diameter) to the lower surface of the filters was scored by staining with $1 \%$ crystal violet. Data were collected from three independent experiments, each measuring at least 12 fields of two different wells.

\section{RT-PCR}

Total RNA was extracted from cultured cells using TRIzol reagent (Invitrogen) according to the manufacturer's protocol and reverse transcribed by M-MLV reverse transcription (Promega) using oligo dT primers at $42^{\circ} \mathrm{C}$ for $60 \mathrm{~min}$. cDNAs were then subjected to 35 cycles of PCR amplification. The primer sequences are listed in Table S1.

\section{Immunofluorescence microscopy}

Immunofluorescence microscopy analysis was performed as described previously (Onodera et al., 2012). For analysis of the subcellular localization of Arf6, cells stably expressing Arf6 proteins with fluorescent tags were plated onto plastic dishes coated with $10 \mu \mathrm{g} / \mathrm{ml}$ collagen I. After $24 \mathrm{~h}$, the cells were serum starved for $16 \mathrm{~h}$ and then stimulated with $2 \mathrm{ng} / \mathrm{ml} \mathrm{TGF} \beta 1$ for $5 \mathrm{~min}$ at $37^{\circ} \mathrm{C}$ before fixation. For analysis of the colocalization of Arf6 and Rab-GTPases, cells expressing Arf6mCherry together with EGFP-Rab11a, or Arf6-EGFP with mRFPRab11b, were used. For analysis of the subcellular localization of Arf6 in HMLE cells, cells were transfected with siRNA for Rab11b or a control oligonucleotide bearing an Irr. After $24 \mathrm{~h}$ of incubation, cells were retrovirally infected with pCX4-blast/Arf6-EGFP or pCX4-blast/ Arf6-mCherry for $24 \mathrm{~h}$. Cells were then cultured for an additional $24 \mathrm{~h}$ with or without $1 \mu \mathrm{M}$ Simvastatin before fixation. Fluorescence images were obtained with a confocal laser-scanning microscope using a $60 \times \mathrm{H}$ oil-immersion objective (NA of 1.4; CFI Plan Apo VC) and analyzed with the attached software (model A1R with NIS-Elements; Nikon). For quantitative analysis of protein colocalization, the Pearson's correlation coefficient between two proteins of interest was measured using NIS-Elements. For the PM localization of Arf6, the Pearson's correlation coefficient of the localization of Arf6-EGFP or Arf6-mCherry at the F-actin-rich cell periphery was measured using NIS-Elements A1R software, in which F-actin was visualized using Alexa Fluor 647 dye. Data were collected from two independent experiments, each examining at least 10 cells. Images were handled using Photoshop (version 7; Adobe).

\section{High-resolution structured illumination microscopy (SIM)}

To examine the colocalization of Arf6 and Rab11, MDA-MB-231 cells expressing Arf6-mCherry and EGFP-Rab11a or Arf6-EGFP and mRFP-Rab11b were also subjected to SIM imaging. Specimens were then analyzed with an N-SIM microscope (Nikon) with an oil-immersion objective $(100 \times / 1.49 \mathrm{NA})$, laser illumination $(488 \mathrm{~nm}$ at $180 \mu \mathrm{W}$ and $561 \mathrm{~nm}$ at $120 \mu \mathrm{W})$, and an electron-multiplying charged-coupled device camera (DU-897; Andor Technology). Image reconstruction was performed using NIS-Elements software.

\section{Deconvolution microscopy}

To examine the colocalization of endogenous Rab11b with Arf6-EGFP, MDA-MB-231 cells stably expressing Arf6-EGFP were plated onto glass-bottom dishes coated with $10 \mu \mathrm{g} / \mathrm{ml}$ collagen I. The cells were then fixed with 4\% PFA in PBS at RT for $10 \mathrm{~min}$, permeabilized with $0.1 \%$ Triton X-100/PBS at RT for $10 \mathrm{~min}$, and then incubated with blocking medium (MAXblock; Active Motif) at RT for $1 \mathrm{~h}$. After washing the cells with PBS, cells were incubated with a rabbit antiRab11b polyclonal antibody (diluted at 1:100; AP12943b; Abgent) at RT for $1 \mathrm{~h}$. After washing with PBS, cells were incubated with Alexa Fluor 555-conjugated F(ab')2 fragments of a goat anti-rabbit polyconal antibody (diluted at 1:400; A-21430; Molecular Probes) at RT for 
$1 \mathrm{~h}$. Cells were then washed with PBS and mounted with 50\% glycerol in PBS. Fluorescent images were acquired with a microscope system (True Confocal Scanning SP8; Leica Biosystems) equipped with HyD detectors and a hybrid superresolution (HyVolution) package using a $63 \times / 1.40$ oil objective (part 15506350; HC PL APO CS2). Z-section images were captured using the HyD detectors, and the raw data were deconvolved using Huygens (Scientific Volume Imaging) that accompanies the HyVolution package and using the default parameters.

\section{Time-lapse recording}

Fluorescence time-lapse imaging was performed under $5 \% \quad \mathrm{CO}_{2}$ at $37^{\circ} \mathrm{C}$ using a confocal laser-scanning microscope with a $60 \times \mathrm{H}$ oil-immersion objective (model A1R with NIS-Elements; CFI Plan Apo VC). Cells stably expressing Arf6-EGFP or Arf6-mCherry were plated onto glass-bottom dishes (MatTek Corporation) in a complete MDA-MB-231 medium and incubated for $24 \mathrm{~h}$ and then transiently transfected with pmRFP-Rab or pEGFP C1-Rab plasmids using Lipofectamine LTX. After further incubation for $24 \mathrm{~h}$, cells were serum starved for $16 \mathrm{~h}$, and their fluorescence images were then taken every $20 \mathrm{~s}$ for $20 \mathrm{~min}$, during which cells were stimulated with $2 \mathrm{ng} / \mathrm{ml}$ TGF $\beta 1$ from just before taking the fourth image. Acquired images were processed with NIS-Elements software and Photoshop.

\section{Inhibition of MVP}

Inhibition of MVP was performed as described previously (Sadeghi et al., 2000). In brief, $5 \mathrm{mg}$ Simvastatin prodrug was dissolved in $0.125 \mathrm{ml}$ of $95 \%$ ethanol followed by $0.15 \mathrm{ml}$ of $0.1 \mathrm{M} \mathrm{NaOH}$, and the solution was incubated at $50^{\circ} \mathrm{C}$ for $2 \mathrm{~h}$ and finally brought to a $\mathrm{pH}$ of 7.2. Working solutions $(1 \mathrm{mM})$ were stored in DMSO at $-80^{\circ} \mathrm{C}$ until use. Final concentrations of the inhibitors used were $100 \mathrm{nM}$ or $1 \mu \mathrm{M}$ for Simvastatin, $100 \mathrm{nM}$ or $1 \mu \mathrm{M}$ for Mevastatin, 20 or $200 \mu \mathrm{M}$ for 6-fluomevalonate, $2 \mu \mathrm{M}$ for GGTI-2133, and $2 \mu \mathrm{M}$ for FTI-277. For the add-back experiment, cells were preincubated with a mixture of $1 \mathrm{mM}$ DL-mevalolactone and $1 \mathrm{mM}$ DL-MVA 5-phosphate for $6 \mathrm{~h}$ and then treated with $1 \mu \mathrm{M}$ Simvastatin. For injection into mice, the activated Simvastatin solution was diluted to the appropriate concentration in sterile PBS without using DMSO in any of the steps, in which the control was a PBS solution containing equivalent amounts of ethanol, $\mathrm{NaOH}$, and $\mathrm{HCl}$ as contained in the injected Simvastatin solution.

\section{Membrane association of Rabl 1 b}

To separate the prenylated and unprenylated forms of Rab11b in MDA-MB-231 cells, a Triton X-114 fractionation method (Coxon et al., 2005) was used. In brief, cells were transfected with pCX4-HARab11b or its C214A/C215A mutant using Lipofectamine LTX according to the manufacturer's instructions (Invitrogen). After $24 \mathrm{~h}$, cells were lysed in Triton X-114 fractionation buffer (20 mM Tris-HCl, $\mathrm{pH} 7.4$, $150 \mathrm{mM} \mathrm{NaCl}, 1 \%$ Triton $\mathrm{X}-114$, and protease inhibitor cocktail [Nakalai]). After clarifying by centrifugation $(13,000 \mathrm{~g})$ at $4^{\circ} \mathrm{C}$ for $15 \mathrm{~min}$, cell lysates were subjected to partitioning into a detergent-rich phase and an aqueous phase by incubating them for $10 \mathrm{~min}$ at $37^{\circ} \mathrm{C}$, which was followed by centrifugation $(13,000 \mathrm{~g})$ at $25^{\circ} \mathrm{C}$ for $5 \mathrm{~min}$. Proteins of each fraction $(10 \mu \mathrm{g}$ each) were then separated by SDS-PAGE $(12 \%$ gel) and subjected to immunoblotting using antibodies against HA.

\section{Lipid raft and cholesterol levels}

To analyze lipid raft localization, cell membrane fractionation was performed using OptiPrep (Axis-Shield) as described previously (Macdonald and Pike, 2005). In brief, cells grown on two 14-cm dishes were washed twice and scraped into ice-cold buffer $(20 \mathrm{mM}$ Tris- $\mathrm{HCl}, \mathrm{pH}$ 7.8, $250 \mathrm{mM}$ sucrose, $1 \mathrm{mM} \mathrm{CaCl}_{2}$, and $1 \mathrm{mM} \mathrm{MgCl}_{2}$ ) and centrifuged at $250 \mathrm{~g}$ for $2 \mathrm{~min}$. Cell pellets were then resuspended in $0.5 \mathrm{ml}$ of the same buffer containing a cocktail of protease inhibitors and ruptured by passage through a 22-gauge needle 50 times and centrifuged at $1,000 \mathrm{~g}$ for $10 \mathrm{~min}$. Supernatants containing $240 \mu \mathrm{g}$ of protein were then adjusted to a final volume of $800 \mu \mathrm{l}$ with the same buffer, mixed with $800 \mu \mathrm{l}$ of $50 \%$ OptiPrep in the same buffer, and placed at the bottom of a centrifuge tube (50 ultra clear 1/2 $\times 2^{\prime \prime}$ tube; Beckman Coulter). A 20-0\% OptiPrep gradient in the same buffer was then made on top of the samples with a total volume of $3,960 \mu$, and the tubes were centrifuged at 52,000 $\mathrm{g}$ for $90 \mathrm{~min}$ using an SW55Ti rotor (Optima L-100XP; Beckman Coulter). After centrifugation, each 300- $\mu$ l fraction was collected from the top of the tubes. All of these steps were performed at $4^{\circ} \mathrm{C} .10 \mathrm{ml}$ of each fraction was then separated by $8 \%$ SDS-PAGE followed by immunoblotting using an anti-Flotillin-1 antibody (610820; BD). For measuring total cellular cholesterol levels, cells grown on a 6-well dish were washed twice with ice-cold PBS and scraped with $100 \mu \mathrm{l}$ of ice-cold lysis solution ( $2 \% n$-octyl- $\beta$-Dglucoside, $1 \%$ Nonidet $\mathrm{P}-40,20 \mathrm{mM}$ Tris- $\mathrm{HCl}, \mathrm{pH}$ 7.4, $150 \mathrm{mM}$ sodium chloride, $1 \mathrm{mM}$ EDTA, $1 \mathrm{mM}$ sodium orthovanadate, $20 \mathrm{mM}$ sodium fluoride, and 5\% glycerol) containing a protease inhibitor cocktail. Lysates were then collected into new tubes, mixed well, and clarified by centrifugation at $4{ }^{\circ} \mathrm{C}$ for $10 \mathrm{~min}$. The amounts of cholesterol in the resulting supernatants containing $1 \mathrm{mg}$ of protein were measured using a cholesterol assay kit (Amplex Red; Molecular Probes) according to the manufacturer's instructions.

\section{Metastasis assay}

$\mathrm{Nu} / \mathrm{Nu}$ athymic mice were obtained from Central Laboratory for Experimental Animals Japan. All experiments were conducted under a protocol approved by the animal care committee of Hokkaido University. MDA-MB-231 cells were lentivirally infected with pLenti CMV V5-Luc blast (21474; Addgene) and pLKO.1-puro shRNA constructs bearing shRNA sequences to knock down Rab11b, which were purchased from an shRNA library (TRCN00000381919; Mission; Sigma-Aldrich). A scrambled shRNA (1864; Addgene) was used as a control. We tried in vain to silence GGT-II by shRNA constructs, which were purchased from an shRNA library (TRCN00000299714; Mission). A total of $2 \times 10^{6}$ cells were injected into the lateral tail vein of each female athymic nude mouse at $5 \mathrm{wk}$ of age. For Simvastatin treatment, MDA-MB-231 cells stably expressing the luciferase gene were pretreated with $1 \mu \mathrm{M}$ Simvastatin or with a control PBS solution for $2 \mathrm{~d}$ before injection. After injection, mice were intraperitoneally injected with $5 \mathrm{mg} / \mathrm{kg}$ body weight of Simvastatin or with a control PBS solution every day for $28 \mathrm{~d}$. For bioluminescence imaging, mice were anesthetized with $3 \%$ isoflurane and injected intraperitoneally with 150 $\mathrm{mg} / \mathrm{kg}$ body weight of D-luciferin in PBS. At $10 \mathrm{~min}$ after the injection, bioluminescence was detected with an in vivo imaging system (Xenogen) and analyzed with living-image software (Xenogen). Photon flux (photons/seconds/square centimeters/steradian) was calculated for each mouse using a region of interest encompassing the thorax. This value was normalized with a comparable background value. For histology, lungs were fixed in $10 \%$ neutral buffered formalin (Wako Pure Chemical Industries). Sections were stained with hematoxylin using standard procedures by Morpho Technology.

\section{Drug resistance assay}

Gemcitabine and Temsirolimus were purchased from Wako Pure Chemical Industries and Sigma-Aldrich, respectively. In the EPB41L5 knockdown experiment, cells pretreated with siRNAs specific for EPB41L5 or a control oligonucleotide for $24 \mathrm{~h}$ were plated onto 96-well culture plates at 3,000 cells per well, and drugs were applied on the next day. After incubation for another $3 \mathrm{~d}$, cell viabilities were measured. 


\section{Statistics}

Unless otherwise noted, each in vitro experiment was performed in triplicate, and analysis of variance was used to compare two groups of independent samples. The log-rank test was used to compare Kaplan-Meier survival curves.

\section{Online supplemental material}

Fig. S1 shows the Arf6 activation mediated by TGF $\beta 1$-trans-activated c-Met. Fig. S2 shows the roles of mutant p53, MVP, and GGT-II in Arf6 activation by external ligands in breast cancer cells. Fig. S3 shows the involvement of Rab11b in the PM recruitment of Arf6 and no effect of mutant p53 in lipid rafts. Fig. S4 shows the silencing of Rab11 in HMLE cells and the requirement of Rab11b and MVP in cancer metastasis. Fig. S5 shows the drug resistance of MDA-MB-468 and MCF7 and limited contribution of the TP53 mutation to the high HMGCR expression group of primary breast tumors. Table S1 contains the oligonucleotides used in this study. Table S2 is a list of siRNA sequences used in this paper. Video 1 shows colocalization of Rab11b with Arf6 during the TGF $\beta 1$-induced PM recruitment of Arf6. Online supplemental material is available at http://www.jcb.org/cgi/content/ full/jcb.201510002/DC1.

\section{Acknowledgments}

We thank Y. Kado, H. Yoshino, and E. Hayashi for their assistance, R.A. Weinberg for the HMLE cells, T. Kitamura for the Plat-E cells, T. Akagi for the pCX4bsr vector, and H.A. Popiel for her critical reading of the manuscript. High-resolution SIM imaging was supported by Nikon.

This work was supported by grants-in-aid from the Ministry of Education, Science, Sports and Culture of Japan (23112008) and grants from the Takeda Science Foundation and the Mitsubishi Foundation to $\mathrm{H}$. Sabe as well as grants from the Akiyama Life Science Foundation, the Suhara Foundation, the Kobayashi Foundation for Cancer Research, and the Princess Takamatsu Cancer Research Fund (13$24517)$ to A. Hashimoto and S. Hashimoto.

The authors declare no competing financial interests.

Submitted: 1 October 2015

Accepted: 4 March 2016

\section{References}

Adorno, M., M. Cordenonsi, M. Montagner, S. Dupont, C. Wong, B. Hann, A. Solari, S. Bobisse, M.B. Rondina, V. Guzzardo, et al. 2009. A Mutant-p53/Smad complex opposes p63 to empower TGF $\beta$-induced metastasis. Cell. 137:87-98. http://dx.doi.org/10.1016/j.cell.2009.01.039

Akagi, T., K. Sasai, and H. Hanafusa. 2003. Refractory nature of normal human diploid fibroblasts with respect to oncogene-mediated transformation. Proc. Natl. Acad. Sci. USA. 100:13567-13572. http://dx.doi.org/10.1073 /pnas. 1834876100

Altwairgi, A.K. 2015. Statins are potential anticancerous agents (review). Oncol. Rep. 33:1019-1039.

Berndt, N., A.D. Hamilton, and S.M. Sebti. 2011. Targeting protein prenylation for cancer therapy. Nat. Rev. Cancer. 11:775-791. http://dx.doi.org/10 $.1038 / \mathrm{nrc} 3151$

Cancer Genome Atlas Network. 2012. Comprehensive molecular portraits of human breast tumours. Nature. 490:61-70. http://dx.doi.org/10.1038/ nature 11412

Coleman, M.P., M. Quaresma, F. Berrino, J.-M. Lutz, R. De Angelis, R. Capocaccia, P. Baili, B. Rachet, G. Gatta, T. Hakulinen, et al. CON CORD Working Group. 2008. Cancer survival in five continents: a worldwide population-based study (CONCORD). Lancet Oncol. 9:730756. http://dx.doi.org/10.1016/S1470-2045(08)70179-7
Coxon, F.P., F.H. Ebetino, E.H. Mules, M.C. Seabra, C.E. McKenna, and M.J. Rogers. 2005. Phosphonocarboxylate inhibitors of Rab geranylgeranyl transferase disrupt the prenylation and membrane localization of Rab proteins in osteoclasts in vitro and in vivo. Bone. 37:349-358. http://dx.doi.org/10.1016/j.bone.2005.04.021

De Benedetti, A., and J.R. Graff. 2004. eIF-4E expression and its role in malignancies and metastases. Oncogene. 23:3189-3199. http://dx.doi.org /10.1038/sj.onc. 1207545

Duggan, D.E., I.W. Chen, W.F. Bayne, R.A. Halpin, C.A. Duncan, M.S. Schwartz, R.J. Stubbs, and S. Vickers. 1989. The physiological disposition of lovastatin. Drug Metab. Dispos. 17:166-173.

Elenbaas, B., L. Spirio, F. Koerner, M.D. Fleming, D.B. Zimonjic, J.L. Donaher, N.C. Popescu, W.C. Hahn, and R.A. Weinberg. 2001. Human breast cancer cells generated by oncogenic transformation of primary mammary epithelial cells. Genes Dev. 15:50-65. http://dx.doi.org/10.1101/gad .828901

Elster, N., D.M. Collins, S. Toomey, J. Crown, A.J. Eustace, and B.T. Hennessy. 2015. HER2-family signalling mechanisms, clinical implications and targeting in breast cancer. Breast Cancer Res. Treat. 149:5-15. http://dx .doi.org/10.1007/s10549-014-3250-X

Endo, A., M. Kuroda, and Y. Tsujita. 1976. ML-236A, ML-236B, and ML-236C, new inhibitors of cholesterogenesis produced by Penicillium citrinium. J. Antibiot. (Tokyo). 29:1346-1348. http://dx.doi.org/10.7164/antibiotics .29 .1346

Faulds, M.H., C. Zhao, K. Dahlman-Wright, and J.-Å. Gustafsson. 2012. The diversity of sex steroid action: regulation of metabolism by estrogen signaling. J. Endocrinol. 212:3-12. http://dx.doi.org/10.1530/JOE-11 $-0044$

Fischer, K.R., A. Durrans, S. Lee, J. Sheng, F. Li, S.T. Wong, H. Choi, T. El Rayes, S. Ryu, J. Troeger, et al. 2015. Epithelial-to-mesenchymal transition is not required for lung metastasis but contributes to chemoresistance. Nature. 527:472-476. http://dx.doi.org/10.1038/nature15748

Freed-Pastor, W.A., H. Mizuno, X. Zhao, A. Langerød, S.-H. Moon, R. Rodriguez-Barrueco, A. Barsotti, A. Chicas, W. Li, A. Polotskaia, et al. 2012. Mutant p53 disrupts mammary tissue architecture via the mevalonate pathway. Cell. 148:244-258. http://dx.doi.org/10.1016/j.cell .2011.12.017

Frisch, S.M., M. Schaller, and B. Cieply. 2013. Mechanisms that link the oncogenic epithelial-mesenchymal transition to suppression of anoikis. J. Cell Sci. 126:21-29. http://dx.doi.org/10.1242/jcs.120907

Goldstein, J.L., and M.S. Brown. 1990. Regulation of the mevalonate pathway. Nature. 343:425-430. http://dx.doi.org/10.1038/343425a0

Grant, B.D., and J.G. Donaldson. 2009. Pathways and mechanisms of endocytic recycling. Nat. Rev. Mol. Cell Biol. 10:597-608. http://dx.doi.org/10 $.1038 / \mathrm{nrm} 2755$

Grunt, T.W., and G.L. Mariani. 2013. Novel approaches for molecular targeted therapy of breast cancer: interfering with PI3K/AKT/mTOR signaling. Curr. Cancer Drug Targets. 13:188-204. http://dx.doi.org/10.2174 /1568009611313020008

Hashimoto, A., S. Hashimoto, R. Ando, K. Noda, E. Ogawa, H. Kotani, M. Hirose, T. Menju, M. Morishige, T. Manabe, et al. 2011. GEP100Arf6-AMAP1-cortactin pathway frequently used in cancer invasion is activated by VEGFR2 to promote angiogenesis. PLoS One. 6:e23359. http://dx.doi.org/10.1371/journal.pone.0023359

Hashimoto, S., A. Hashimoto, A. Yamada, C. Kojima, H. Yamamoto, T. Tsutsumi, M. Higashi, A. Mizoguchi, R. Yagi, and H. Sabe. 2004b. A novel mode of action of an ArfGAP, AMAP2/PAG3/Papo, in Arf6 function. J. Biol. Chem. 279:37677-37684. http://dx.doi.org/10.1074/jbc.M404196200

Hashimoto, S., Y. Onodera, A. Hashimoto, M. Tanaka, M. Hamaguchi, A. Yamada, and H. Sabe. 2004a. Requirement for Arf6 in breast cancer invasive activities. Proc. Natl. Acad. Sci. USA. 101:6647-6652. http://dx .doi.org/10.1073/pnas.0401753101

Hashimoto, S., M. Hirose, A. Hashimoto, M. Morishige, A. Yamada, H. Hosaka, K. Akagi, E. Ogawa, C. Oneyama, T. Agatsuma, et al. 2006. Targeting AMAP1 and cortactin binding bearing an atypical src homology 3/ proline interface for prevention of breast cancer invasion and metastasis. Proc. Natl. Acad. Sci. USA. 103:7036-7041. http://dx.doi.org/10.1073/ pnas.0509166103

Hashimoto, S., S. Mikami, H. Sugino, A. Yoshikawa, A. Hashimoto, Y. Onodera, S. Furukawa, H. Handa, T. Oikawa, Y. Okada, et al. 2016. Lysophosphatidic acid activates Arf6 to promote the mesenchymal malignancy of renal cancer. Nat. Commun. 7:10656. http://dx.doi.org/10 $.1038 /$ ncomms 10656

Hirano, M., S. Hashimoto, S. Yonemura, H. Sabe, and S. Aizawa. 2008. EPB41L5 functions to post-transcriptionally regulate cadherin and integrin during epithelial-mesenchymal transition. J. Cell Biol. 182:1217-1230. http://dx .doi.org/10.1083/jcb.200712086 
Irwin, M.E., K.L. Mueller, N. Bohin, Y. Ge, and J.L. Boerner. 2011. Lipid raft localization of EGFR alters the response of cancer cells to the EGFR tyrosine kinase inhibitor gefitinib. J. Cell. Physiol. 226:2316-2328. http://dx.doi.org/10.1002/jcp. 22570

Jukema, J.W., C.P. Cannon, A.J. de Craen, R.G. Westendorp, and S. Trompet. 2012. The controversies of statin therapy: weighing the evidence. J. Am. Coll. Cardiol. 60:875-881. http://dx.doi.org/10.1016/j.jacc.2012.07.007

Kinoshita, R., J.M. Nam, Y.M. Ito, K.C. Hatanaka, A. Hashimoto, H. Handa, Y. Otsuka, S. Hashimoto, Y. Onodera, M. Hosoda, et al. 2013. Cooverexpression of GEP100 and AMAP1 proteins correlates with rapid local recurrence after breast conservative therapy. PLoS One. 8:e76791. http://dx.doi.org/10.1371/journal.pone.0076791

Li, Y.C., M.J. Park, S.K. Ye, C.W. Kim, and Y.N. Kim. 2006. Elevated levels of cholesterol-rich lipid rafts in cancer cells are correlated with apoptosis sensitivity induced by cholesterol-depleting agents. Am. J. Pathol. 168:1107-1118. http://dx.doi.org/10.2353/ajpath.2006.050959

Macdonald, J.L., and L.J. Pike. 2005. A simplified method for the preparation of detergent-free lipid rafts. J. Lipid Res. 46:1061-1067. http://dx.doi.org /10.1194/jlr.D400041-JLR200

Maring, J.G., H.J. Groen, F.M. Wachters, D.R. Uges, and E.G. de Vries. 2005. Genetic factors influencing pyrimidine-antagonist chemotherapy. Pharmacogenomics J. 5:226-243. http://dx.doi.org/10.1038/sj.tpj.6500320

Matsui, T., T. Itoh, and M. Fukuda. 2011. Small GTPase Rab12 regulates constitutive degradation of transferrin receptor. Traffic. 12:1432-1443. http://dx.doi.org/10.1111/j.1600-0854.2011.01240.x

Menju, T., S. Hashimoto, A. Hashimoto, Y. Otsuka, H. Handa, E. Ogawa, Y. Toda, H. Wada, H. Date, and H. Sabe. 2011. Engagement of overexpressed Her2 with GEP100 induces autonomous invasive activities and provides a biomarker for metastases of lung adenocarcinoma. PLoS One. 6:e25301. http://dx.doi.org/10.1371/journal.pone.0025301

Moffat, J., D.A. Grueneberg, X. Yang, S.Y. Kim, A.M. Kloepfer, G. Hinkle, B. Piqani, T.M. Eisenhaure, B. Luo, J.K. Grenier, et al. 2006. A lentiviral RNAi library for human and mouse genes applied to an arrayed viral high-content screen. Cell. 124:1283-1298. http://dx.doi.org/10.1016/j .cell.2006.01.040

Morgenstern, J.P., and H. Land. 1990. Advanced mammalian gene transfer: high titre retroviral vectors with multiple drug selection markers and a complementary helper-free packaging cell line. Nucleic Acids Res. 18:3587-3596. http://dx.doi.org/10.1093/nar/18.12.3587

Morishige, M., S. Hashimoto, E. Ogawa, Y. Toda, H. Kotani, M. Hirose, S. Wei, A. Hashimoto, A. Yamada, H. Yano, et al. 2008. GEP100 links epidermal growth factor receptor signalling to Arf6 activation to induce breast cancer invasion. Nat. Cell Biol. 10:85-92. http://dx.doi.org/10.1038/ ncb1672

Nezasa, K., A. Takao, K. Kimura, M. Takaichi, K. Inazawa, and M. Koike. 2002. Pharmacokinetics and disposition of rosuvastatin, a new 3-hydroxy3-methylglutaryl coenzyme A reductase inhibitor, in rat. Xenobiotica. 32:715-727. http://dx.doi.org/10.1080/00498250210144820

Ocaña, A., E. Amir, B. Seruga, M. Martin, and A. Pandiella. 2013. The evolving landscape of protein kinases in breast cancer: clinical implications. Cancer Treat. Rev. 39:68-76. http://dx.doi.org/10.1016/j.ctrv.2012.05.004

Onodera, Y., S. Hashimoto, A. Hashimoto, M. Morishige, Y. Mazaki, A. Yamada, E. Ogawa, M. Adachi, T. Sakurai, T. Manabe, et al. 2005. Expression of AMAP1, an ArfGAP, provides novel targets to inhibit breast cancer invasive activities. EMBO J. 24:963-973. http://dx.doi.org/10.1038/sj .emboj.7600588
Onodera, Y., J.M. Nam, A. Hashimoto, J.C. Norman, H. Shirato, S. Hashimoto, and H. Sabe. 2012. Rab5c promotes AMAP1-PRKD2 complex formation to enhance $\beta 1$ integrin recycling in EGF-induced cancer invasion. J. Cell Biol. 197:983-996. http://dx.doi.org/10.1083/jcb.201201065

Sadeghi, M.M., M. Collinge, R. Pardi, and J.R. Bender. 2000. Simvastatin modulates cytokine-mediated endothelial cell adhesion molecule induction: involvement of an inhibitory G protein. J. Immunol. 165:27122718. http://dx.doi.org/10.4049/jimmunol.165.5.2712

Sato, H., K.C. Hatanaka, Y. Hatanaka, H. Hatakeyama, A. Hashimoto, Y. Matsuno, S. Fukuda, and H. Sabe. 2014. High level expression of AMAP1 protein correlates with poor prognosis and survival after surgery of head and neck squamous cell carcinoma patients. Cell Commun. Signal. 12:17. http://dx .doi.org/10.1186/1478-811X-12-17

Shibata, M.A., Y. Ito, J. Morimoto, and Y. Otsuki. 2004. Lovastatin inhibits tumor growth and lung metastasis in mouse mammary carcinoma model: a p53-independent mitochondrial-mediated apoptotic mechanism. Carcinogenesis. 25:1887-1898. http://dx.doi.org/10.1093/carcin/bgh201

Stenmark, H. 2009. Rab GTPases as coordinators of vesicle traffic. Nat. Rev. Mol. Cell Biol. 10:513-525. http://dx.doi.org/10.1038/nrm2728

Tryndyak, V.P., F.A. Beland, and I.P. Pogribny. 2010. E-cadherin transcriptional down-regulation by epigenetic and microRNA-200 family alterations is related to mesenchymal and drug-resistant phenotypes in human breast cancer cells. Int. J. Cancer. 126:2575-2583.

Uchiyama-Tanaka, Y., H. Matsubara, Y. Mori, A. Kosaki, N. Kishimoto, K. Amano, S. Higashiyama, and T. Iwasaka. 2002. Involvement of HBEGF and EGF receptor transactivation in TGF- $\beta$-mediated fibronectin expression in mesangial cells. Kidney Int. 62:799-808. http://dx.doi.org /10.1046/j.1523-1755.2002.00537.x

Vickers, S., C.A. Duncan, I.W. Chen, A. Rosegay, and D.E. Duggan. 1990. Metabolic disposition studies on simvastatin, a cholesterol-lowering prodrug. Drug Metab. Dispos. 18:138-145.

Wasielewski, M., F. Elstrodt, J.G. Klijn, E.M. Berns, and M. Schutte. 2006. Thirteen new p53 gene mutants identified among 41 human breast cancer cell lines. Breast Cancer Res. Treat. 99:97-101. http://dx.doi.org/10.1007 /s10549-006-9186-Z

Wiemer, A.J., D.F. Wiemer, and R.J. Hohl. 2011. Geranylgeranyl diphosphate synthase: an emerging therapeutic target. Clin. Pharmacol. Ther. 90:804812. http://dx.doi.org/10.1038/clpt.2011.215

Yeganeh, B., E. Wiechec, S.R. Ande, P. Sharma, A.R. Moghadam, M. Post, D.H. Freed, M. Hashemi, S. Shojaei, A.A. Zeki, and S. Ghavami. 2014. Targeting the mevalonate cascade as a new therapeutic approach in heart disease, cancer and pulmonary disease. Pharmacol. Ther. 143:87-110. http://dx.doi.org/10.1016/j.pharmthera.2014.02.007

Yu, M., A. Bardia, B.S. Wittner, S.L. Stott, M.E. Smas, D.T. Ting, S.J. Isakoff, J.C. Ciciliano, M.N. Wells, A.M. Shah, et al. 2013. Circulating breast tumor cells exhibit dynamic changes in epithelial and mesenchymal composition. Science. 339:580-584. http://dx.doi.org/10.1126/science .1228522

Zheng, X., J.L. Carstens, J. Kim, M. Scheible, J. Kaye, H. Sugimoto, C.C. Wu, V.S. LeBleu, and R. Kalluri. 2015. Epithelial-to-mesenchymal transition is dispensable for metastasis but induces chemoresistance in pancreatic cancer. Nature. 527:525-530. http://dx.doi.org/10.1038/nature16064

Zhou, X., E.J. Born, C. Allen, S.A. Holstein, and D.F. Wiemer. 2015. N-Oxide derivatives of 3-(3-pyridyl)-2-phosphonopropanoic acids as potential inhibitors of Rab geranylgeranylation. Bioorg. Med. Chem. Lett. 25:2331-2334. http://dx.doi.org/10.1016/j.bmcl.2015.04.021 